\title{
Solar Energy
}

Procedia IUTAM 00 (2014) 000-000

\section{A hierarchical architecture for increasing efficiency of large photovoltaic plants under non-homogeneous solar irradiation}

\author{
Thanh Ngo Ngoc ${ }^{\mathrm{ab}}$, Eleonora Riva Sanseverino ${ }^{\mathrm{c} *}, \mathrm{Ninh}_{\mathrm{Nguyen}} \mathrm{Quang}^{\mathrm{d}}$, Pietro Romano ${ }^{\mathrm{c}}$, \\ Fabio Viola ${ }^{\mathrm{c}}$, Binh Doan Van ${ }^{\mathrm{d}}$, Hoang Nguyen Huy ${ }^{\mathrm{a}}$, Thang Tran Trong ${ }^{\mathrm{a}}$, Quang Nguyen \\ Phung \\ ${ }^{a}$ Electric Power University, HaNoi, VietNam \\ ${ }^{b}$ Graduate University of Science and Technology, Vietnam Academy of Science and Technology \\ ${ }^{c}$ DEIM, University of Palermo, Palermo, Italy \\ ${ }^{d}$ Institute of Energy Science, Vietnam Academy of Science and Technology \\ ${ }^{e}$ Hanoi University of Science and Technology, HaNoi, VietNam
}

\begin{abstract}
Under non-homogeneous solar irradiation, photovoltaic (PV) panels receive different solar irradiance, resulting in a decrease in efficiency of the PV generation system. There are a few technical options to fix this issue that goes under the name of mismatch. One of these is the reconfiguration of the PV generation system, namely changing the connections of the PV panels from the initial configuration to the optimal one. Such technique has been widely considered for small systems, due to the excessive number of required switches. In this paper, the authors propose a new method for increasing the efficiency of large PV systems under nonhomogeneous solar irradiation using Series-Parallel (SP) topology. In the first part of the paper, the authors propose a method containing two key points: a switching matrix to change the connection of PV panels based on SP topology; the demonstration that the SP-based reconfiguration method can increase the efficiency of the photovoltaic system up to $50 \%$. In the second part, the authors propose the extension of the method proposed in the first part to improve the efficiency of large solar generation systems by means of a two-levels architecture to minimize the cost of fabrication of the switching matrix.
\end{abstract}

○2015 Elsevier Ltd. All rights reserved.

Keywords:Mismatch, Photovoltaic modules, Optimization, Reconfiguration.

\section{Nomenclature}

\begin{tabular}{|ll}
\hline EI & Equalization Index \\
$\mathrm{N}$ & number of panels \\
$\mathrm{i}$ & row index \\
$\mathrm{I}-\mathrm{V}$ & current-voltage
\end{tabular}

2210-9838 @ 2014 The Authors. Published by Elsevier B.V.

Selection and peer-review under responsibility of ABCM (Brazilian Society of Mechanical Sciences and Engineering). 


\begin{tabular}{l|ll}
32 & $\mathrm{j}$ & column index \\
33 & $\mathrm{~m}$ & number of rows \\
34 & $\mathrm{MPP}$ & maximum power point \\
35 & $\mathrm{MPPT}$ & Maximum power point tracker \\
36 & $\mathrm{n}_{\mathrm{i}}$ & number of modules that are parallel connected of the row $\mathrm{i}$ \\
37 & $\mathrm{G}$ & total irradiance \\
38 & $\mathrm{P}-\mathrm{V}$ & power-voltage \\
39 & $\mathrm{G}_{\mathrm{i}}$ & total irradiance of the row $\mathrm{i}$ \\
40 & $\mathrm{G}_{\mathrm{ij}}$ & irradiance value of module located on row $\mathrm{i}$ and column $\mathrm{j}$ \\
41 & $\mathrm{PS}$ & partial shading \\
42 & $\mathrm{PV}$ & photovoltaic \\
43 & $\mathrm{TCT}$ & Total-cross-tied \\
44 & $\mathrm{MAA}$ & Munkres' Assignment Algorithm \\
45 & $\mathrm{DP}$ & Dynamic programming \\
46 & $\mathrm{SC}$ & Smartchoice
\end{tabular}

\section{Introduction}

Currently, solar energy plays a very important role in global energy development. It is the green source with largest potential in renewable energy. Besides, direct conversion of solar radiation into electricity, without emission of greenhouse gases, through solar panels may bring the power generation closer to the loads, providing electricity in remote areas where the main power grid cannot reach. However, the investment cost for the solar panels is still high, although decreasing, and the performance is still low, leading to strong research on solar energy technology, to reduce costs and help the solar energy to compete with other renewable energy sources in the future $[1,2]$.

In recent times, a large part of the published works are aimed at the identification of Maximum Power Point Tracking (MPPT) [3-12] algorithms.

However, during operation, the solar panels may work with different performance levels, in particular, due to the heterogeneous lighting, when they are partly covered by shadow of clouds, trees, buildings. In addition, it is possible due to the aging and failure of the solar panels, after a long period of use, that the applied MPPT technology is inefficient, reducing the performance of the entire solar energy system [13,14]. The non homogeneous working conditions of solar panels indeed causes the appearance of multiple optima in the P-V curve and the so-called hotspot phenomenon on the photovoltaic cells that are shaded, causing direct harm to the photovoltaic panel $[15,16]$.

In recent years, many studies have dealt with this issue and have proposed, as a possible solution, the reconfiguration of the PV generator topology [17-21]; on the same topic, the authors also proposed other methods [22-24]. In essence, the reconfiguration of the PV system consists in changing the connections of the solar panels to achieve an optimum configuration, thus providing the maximum systems' generated power. Currently, the reconfiguration is applied for 2 main connection topologies of PV systems: Series-Parallel (SP) and Total-Cross-Tied (TCT) configurations. In the works [22-24], the authors proposed a reconfiguration method for improving the efficiency of the solar energy system under Total-Cross-Tied (TCT) connection. In this article, the authors propose a reconfiguration method for large PV systems based on a hierarchical approach. The basic topology at the two levels is different. SP at the lower level and TCT at the higher level. The underlying idea is that this topology is currently the most adopted for existing solar PV generation systems. Moreover, it may happen that the lower level topology (small perturbations in irradiation) may not change significantly while the upper level topology is the TCT.

Another important contribution of this paper is the proposal of a new switching matrix for reconfiguration PV system using SP topology. Based on that, an optimum configuration selection method is considered. The latter has been implemented in Matlab Simulink environment both for SP and TCT configuration. Then an experiment was 
carried out on a small $1 \mathrm{~kW}$ peak solar energy system. Finally, the authors propose a method for applying the reconfiguration strategy over larger solar PV systems hosting many PV panels. By Matlab simulation, it is proved that a medium size PV system (60 PV panels), using a hierarchical reconfiguration combining TCT and SP topologies, increases its output power for more than $50 \%$ as compared to the same system not using reconfiguration.

Paper is divided in the following sections: paragraph 2 recalls the more diffused reconfiguration strategies; section 3 proposes a novel reconfiguration topology; paragraph 4 describes the experimental setup for reconfiguration algorithm; section 5 deals with the application of reconfiguration strategy for a large PV system; finally section 6 concludes the paper.

\section{Reconfiguration strategies}

It is well known that reconfiguration is a measure devoted to mitigate the mismatch effect and maximize the output power of small photovoltaic plants under non-homogeneous working conditions. Therefore, reconfiguration means changing the connections of the solar panels adaptively by a dynamic switching matrix. Although many convenient interconnection topologies have been developed, so far the most exploited solutions rely on TCT (Fig. 1a) and SP (Fig. 1b) module interconnections. A broad state of the art on the subject is reported in [17].

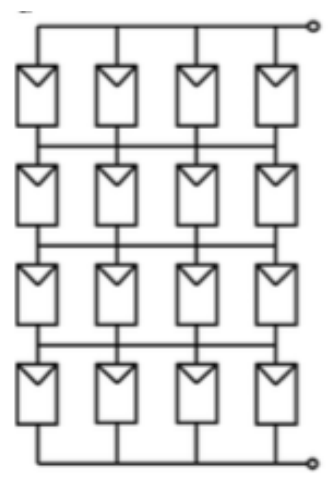

(a)

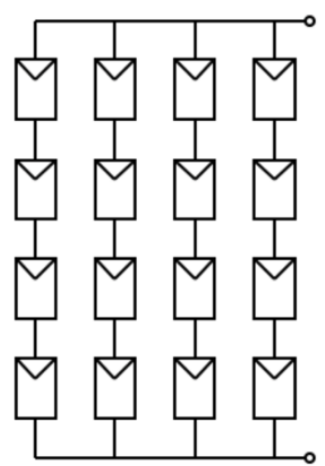

(b)

Fig 1. Connection topologies of the PV array (a) Total-cross-tied topology (b) Series-Parallel

\section{$2.1 \quad$ Reconfiguration for TCT topology}

In the works [22-24], the authors proposed a reconfiguration method for improving the efficiency of PV systems using Total-Cross-Tied (TCT) topology, based on the irradiance equalization criterion. Irradiance equalization is achieved by changing the connections of the solar panels adaptively by a dynamic switching matrix so that total solar radiation on parallel circuits is the most equalized. Efficiency of this method is shown in Fig.2. After reconfiguration, efficiency of the system increases by $14.1 \%$ and transfer from the initial configuration to the optimal one needs only 3 switching operations. 


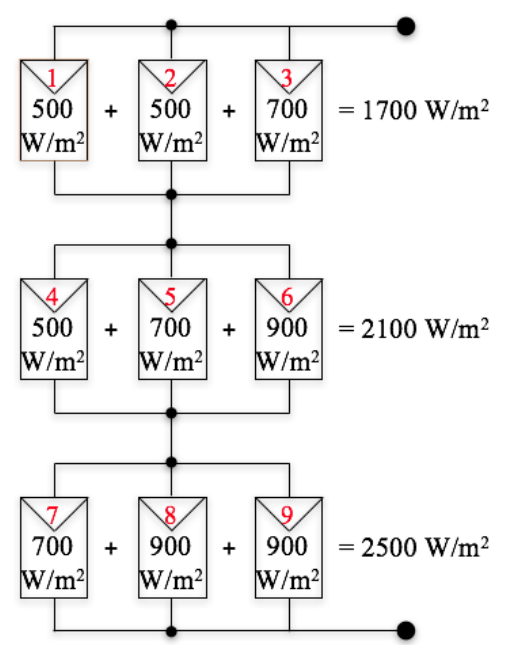

(a) TCT connection circuit before reconfiguration Global I-V \& P-V characteristics
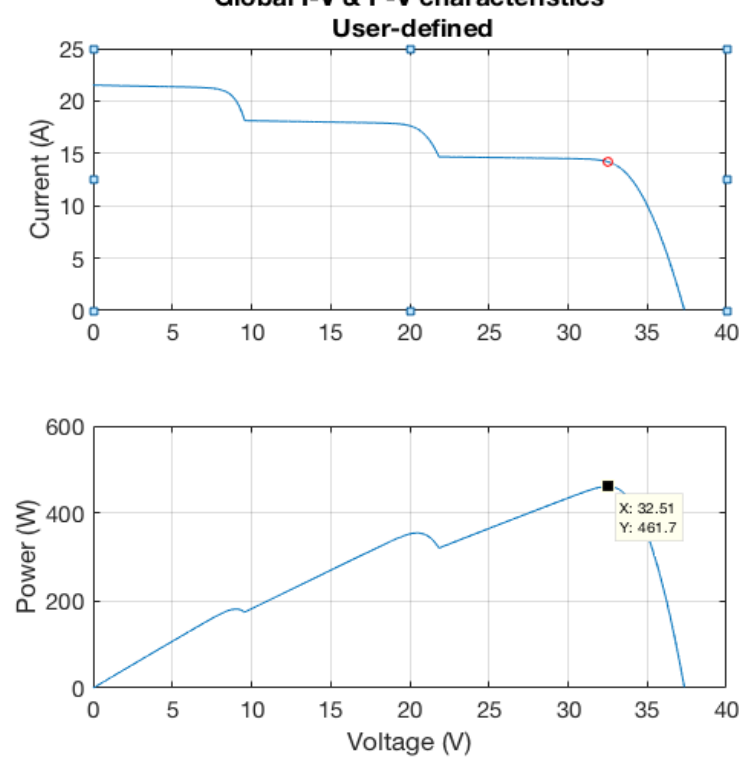

(b) I-V and P-V characteristic before reconfiguration $\left(\mathrm{P}_{\mathrm{MPPT}}=461.7 \mathrm{~W}\right)$

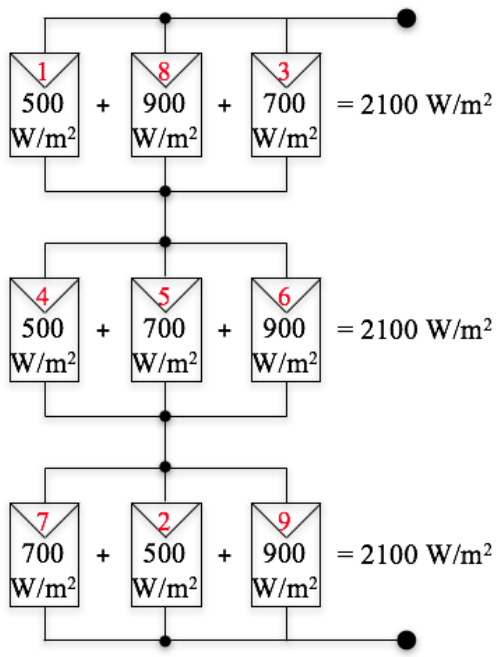

(c) TCT connection circuit after reconfiguration Global I-V \& P-V characteristics
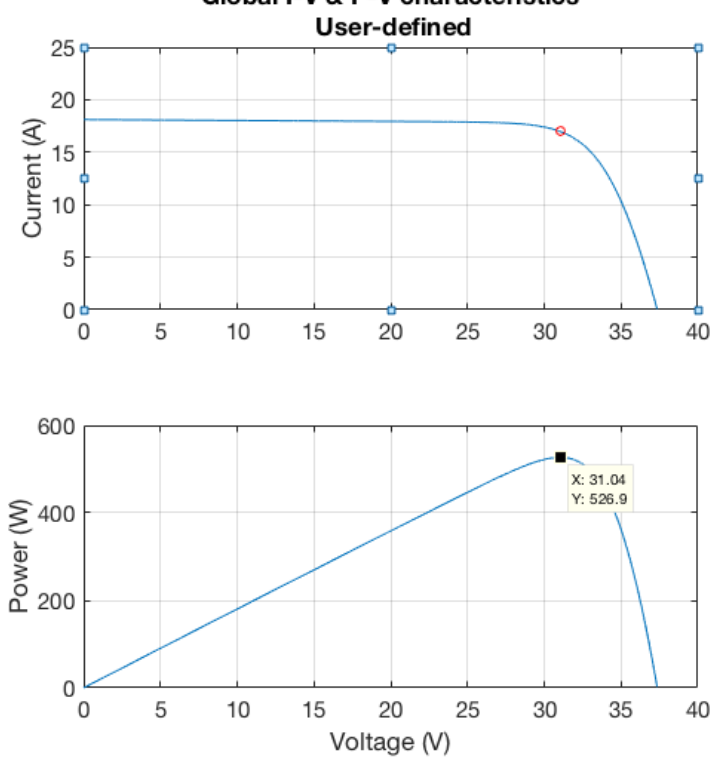

(d) $\mathrm{I}-\mathrm{V}$ and $\mathrm{P}-\mathrm{V}$ characteristic after reconfiguration $\left(\mathrm{P}_{\mathrm{MPPT}}=\right.$ $526.9 \mathrm{~W}$ )

99 Fig 2. PV system (a) and I-V P-V characteristic (b) before reconfiguration; PV system (c) and I-V P-V characteristic (d) after reconfiguration

100

\subsection{Reconfiguration for SP topology}

In the SP topology, the solar PV panels are connected in series, the strings of series connected panels are then connected in parallel according to the SP connection, see Fig.1b. Most solar energy systems use SP connection circuits, for the purpose of serial voltage boosting. Strings are then connected in parallel with the purpose of increasing the current, ensuring the DC output is feasible for either DC/DC or DC/AC conversion. However, during operation, in a serial circuit, when a solar panel is partially or entirely shaded, low operating efficiency becomes a Hotspot, thus consuming the power generated by higher performance solar panels [25]. Bypass diodes, mounted in each group of cells, are designed to avoid this phenomenon cutting off the power generated by the solar panel. Reconfiguration by means of SP topology aims to build strings of series-connected modules with similar irradiance levels and then 
connecting all these strings in parallel. In this way, well-irradiated solar panels will not be limited in current by a low irradiance panel of the same string [17] [26].

A Matlab simulation was run with the same case in section 2.1, connected in SP topology, shown in Fig 3, choosing PV panels Schüco International KG MPE 240 PS 04. The rating of each panel is reported in Table 1. At rated temperature $25^{\circ} \mathrm{C}$, the I-V and P-V characteristics of the PV system in Fig 3a and Fig $3 \mathrm{~b}$ are shown in Fig 3c and Fig 3d. Before reconfiguration $\mathrm{P}_{\mathrm{MPPT}}=456$ (Fig 3c) and after reconfiguration (Fig 3d) $\mathrm{P}_{\mathrm{MPPT}}=526.9 \mathrm{~W}$, increasing the efficiency of $15.54 \%$.

Table 1. Electrical Characteristics of Schüco International KG MPE 240 PS 04

\begin{tabular}{|c|c|c|c|c|}
\hline $\mathrm{V}_{\mathrm{MPP}}$ & $\mathrm{I}_{\mathrm{MPP}}$ & $\mathrm{P}_{\mathrm{MPP}}$ & $\mathrm{V}_{\mathrm{OC}}$ & $\mathrm{I}_{\mathrm{SC}}$ \\
\hline $30.4 \mathrm{~V}$ & $7.91 \mathrm{~A}$ & $240 \mathrm{~W}$ & $37 \mathrm{~V}$ & $8.61 \mathrm{~A}$ \\
\hline
\end{tabular}

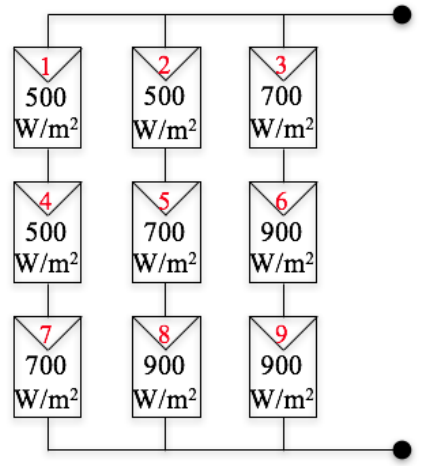

(a) SP connection circuit before reconfiguration Global I-V \& P-V characteristics User-defined
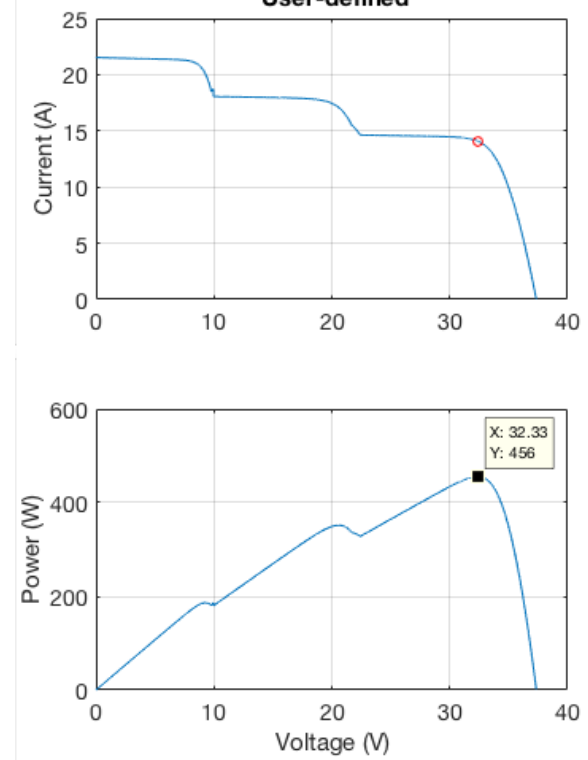

(b) I-V and P-V characteristic before reconfiguration $\left(\mathrm{P}_{\mathrm{MPPT}}=456 \mathrm{~W}\right)$

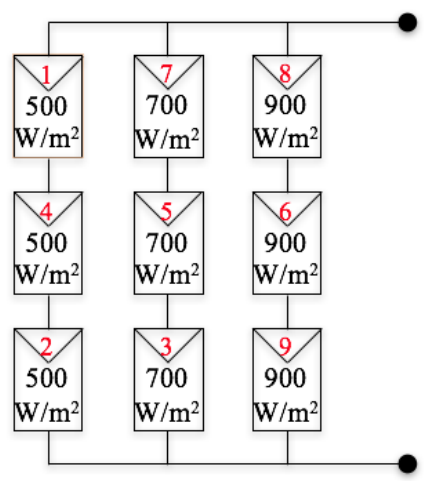

(c) SP connection circuit after reconfiguration Global I-V \& P-V characteristics
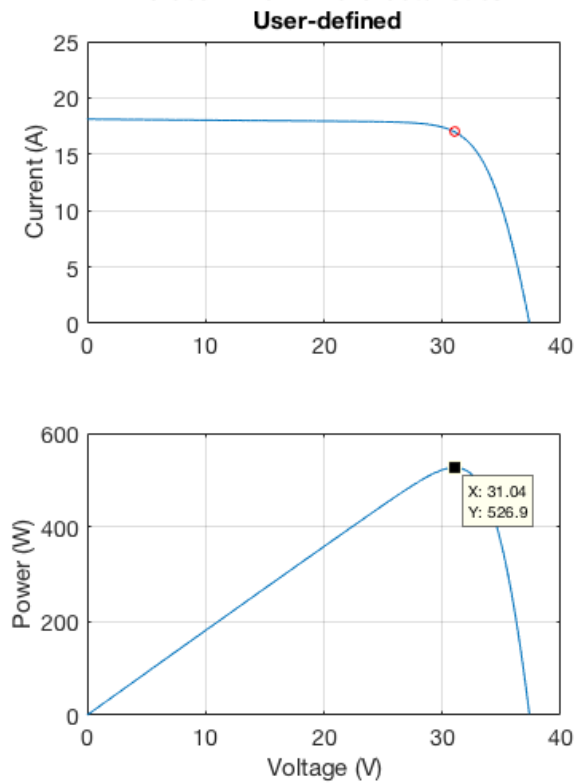

(d) I-V and P-V characteristic after reconfiguration $\left(\mathrm{P}_{\mathrm{MPPT}}=\right.$ $526.9 \mathrm{~W})$ 
As it can be observed, the TCT configuration provides in general improved results in terms of output power, as compared to SP. In this paper, the two topologies were used starting from a centralized architecture of a large PV field, trying to minimize the cabling and avoid the change of the central inverter.

\section{Proposed method for optimal photovoltaic array reconfiguration using SP topology}

\subsection{Switching matrix}

For this particular application, the switching matrix is designed to include circuit breakers so that with proper opening and closing operation, it is possible to change the connection position of the solar panels in the SP connection circuit.

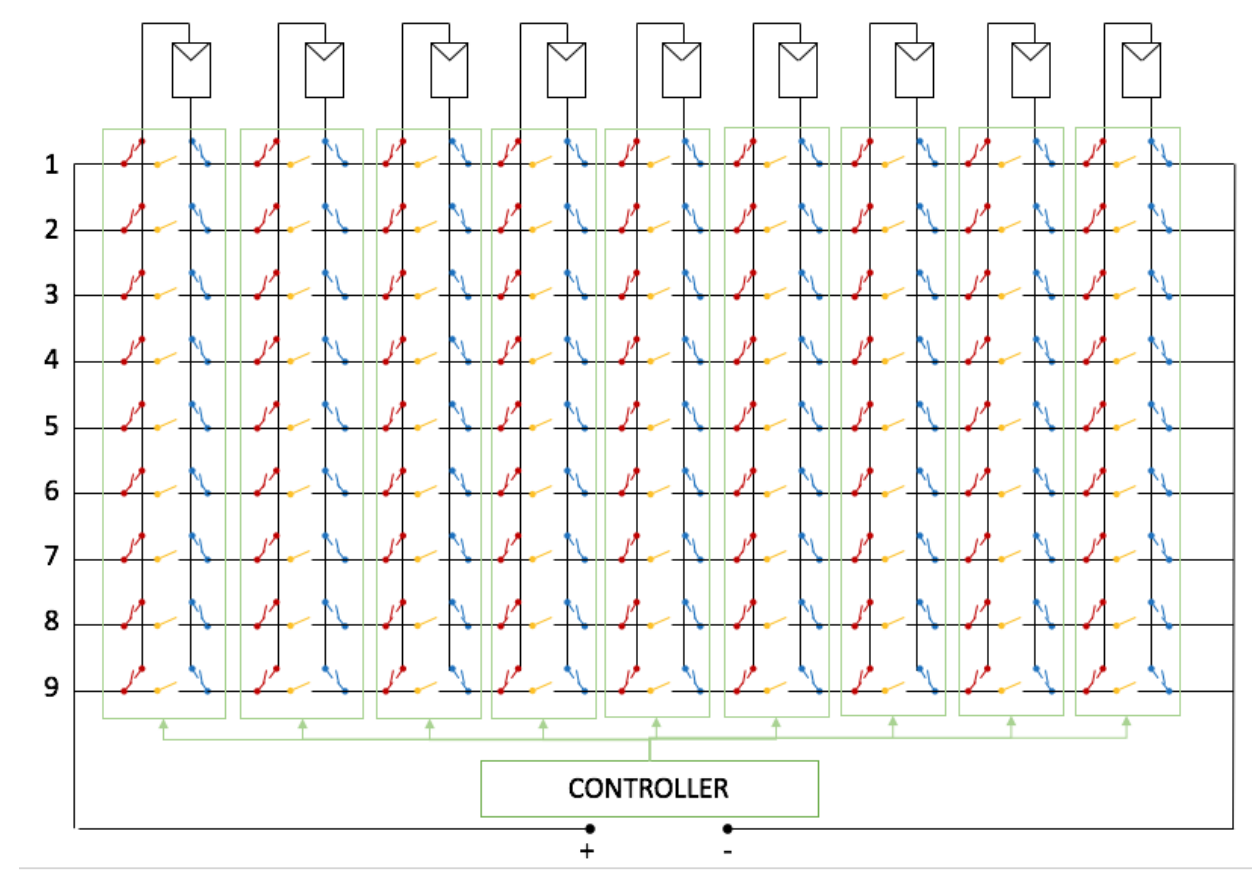

Fig 4. Switching matrix

The proposed switching matrix is designed, see Fig. 4, so that each PV panel needs 3 switches on each row, hence with the switching matrix, the configuration of the PV system can be changed completely. The number of switches is $\mathrm{N} 3 \mathrm{x} \mathrm{M}$ where $\mathrm{N}$ is the number of $\mathrm{PV}$ panels, $\mathrm{M}$ is maximum number of series connected PV panels.

The switching matrix differences with others switching matrix proposed. In [34] the authors proposed switching matrix which can sorts the system's strings into two categories: the main PV string (MPV), which forms complete strings with the proper number of modules, and the sub-PV string, which forms a partial string that consists of the remaining PV modules that do not meet the required number to form an MPV. In operation, shaded PV modules are connect to DC/DC inverter in string; other PV modules do not change position. If there are no partial strings and hence the DC/DC bus and converter is not utilized. Not able change connection for fully configuration.

Each solar panel may connect to the serial circuits (Fig. 1b) with different switch sets, each set with 3 switches, positive pole switch (red), negative pole switch (blue), and line switch (yellow).

To create the SP configuration, and in particular the serial circuit, the positive pole switch and the negative pole switch on the circuit are closed, while the two poles of the parallel connection are activated using the line switches 
connected to the two black vertical metallic connections. With the opening and closing of the different switches sets, the original connection of the solar panels will change, creating a new connection circuit to ensure the overall structure is still SP but the solar panel can gain a different position.

\subsection{SP-based reconfiguration method}

The general method for improving the efficiency of the PV systems using the SP connection circuit is depicted in Fig. 5.

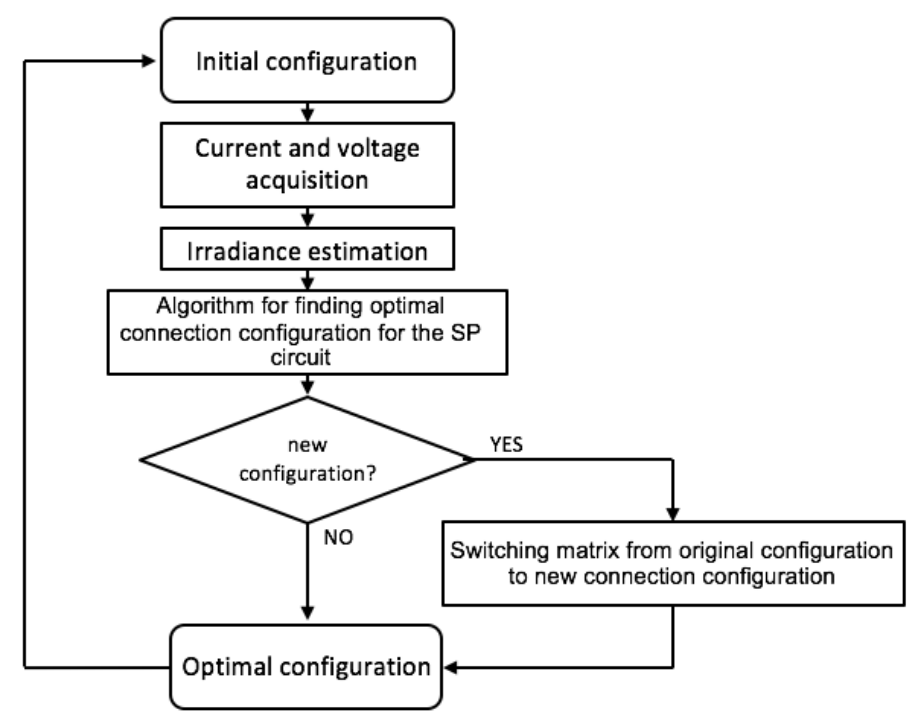

Fig 5. Scheme of optimal reconfiguration for SP connection PV circuits

The order of execution of each of the steps represented in Fig. 5 is outlined below.

Steps 1-2: From the initial connection configuration, using current and voltage measuring devices, current and voltage of each solar panel is acquired.

Step 3: The irradiance is deducted starting from measured values. To do so, the solar irradiance estimation is thus assessed:

$$
\left.G=\frac{G_{S T C}}{I_{L_{S T C}}+\mu_{1}\left(T_{C}-T_{C} T C\right.}\right)\left[I+I_{0}\left(e^{\frac{V+I R_{S}}{N_{S} A k \frac{T_{C}}{q}}}-1\right)+\frac{V+I R_{S}}{R_{S h}}\right]
$$

Where:

$\mathrm{G}$ is the solar irradiance measured in $\mathrm{W} / \mathrm{m}^{2}$,

I, V respectively are the measured current and voltage of the solar panel,

$\mathrm{G}_{\text {STC }}$ the solar irradiance in standard conditions,

$I_{L_{S T C}}$ is the PV cell light-generated current at STC, 
$\mu_{1 s c}$ is the short-circuit current temperature coefficient,

$T_{c}$ the temperature of cell,

$T_{C_{S T C}}$ the temperature at STC $(298.15 \mathrm{~K})$,

$I_{0}$ the diode reverse saturation current,

$R_{S}$ and $R_{S H}$ respectively the cell series and shunt resistance,

$N_{S}$ the number of cells series-connected,

$A$ the ideality factor,

$k$ is the Boltzmann's constant,

$q$ the electron charge,

$T_{c}$ the temperature of cell.

The irradiance of each solar panel, is based on acquired parameters and measured current and voltage as in [27],

Step 4: Application of the optimal connection configuration algorithm for the SP connection circuit and finding of the connection configuration for the best performance of the solar plant.

Step 5: Checking of the optimal connection configuration against the initial connection configuration, if there is sufficiently large (to be defined within prescribed tolerance) improvement, control the switching matrix to change the connection of the solar energy system from the initial connection to the optimal connection.

\subsection{Algorithm for finding optimal configuration in SP topology}

Many articles propose a method for optimal reconfiguration based on SP topology, [28-31]. In this paper, the algorithm for finding the optimum connection configuration suggests the new location of the solar panels so that after their rearrangement, the solar panels on the same series circuit have the least solar irradiance difference.

The difference in irradiance between the solar panels in the serial circuit is proportional to the difference in current generated between the panels. In the ideal case, $\mathrm{n}$ solar panels in serial circuits have the same solar irradiance. In the real case, it may happen that some of them experience a different irradiance level. If $\mathrm{G}_{\mathrm{ij}}$ is the irradiance on the solar panel at row $i$ and column $j$ in the SP connection circuit, the maximum irradiance difference in a serial circuit $j$ can be calculated using equation (2) as follows:

$$
E I_{j}=\max \left(G_{i j}\right)-\min \left(G_{i j}\right) \quad \forall j=1, \ldots, n
$$

The goal function of the algorithm is to minimize the maximum difference that can be appreciated, as follows:

$$
E I=\min \left(\max \left(E I_{j}\right)\right) \quad \forall j=1, \ldots, m
$$

Thus, the configuration with the lowest value of EI is the optimal configuration. In the case of multiple configurations with the same EI, configurations attainable with the minimum number of switching operations will be selected.

The flowchart shown in Fig. 6 depicts the process. 


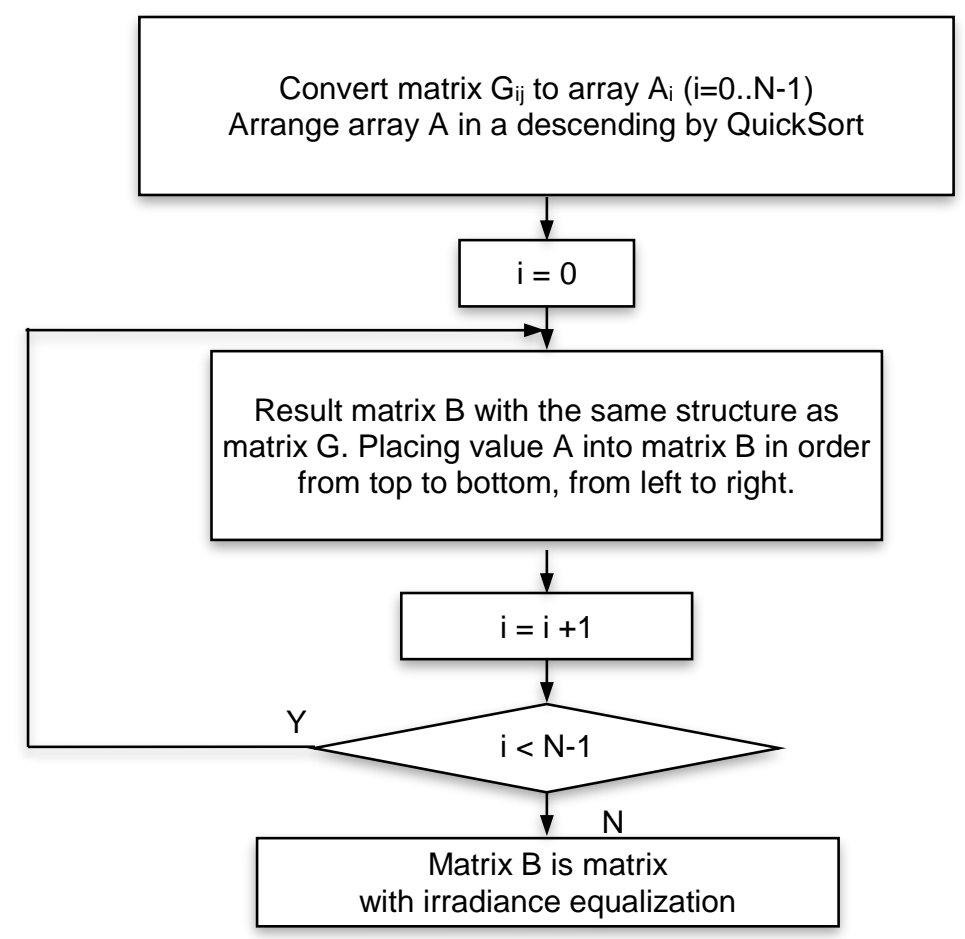

Fig 6. Scheme of an algorithm for finding the optimal connection configuration of the SP circuit

The algorithm will be explained for the SP connection. Consider the general solar PV system in Fig. 3a.

The panel in row $\mathrm{i}$, column $\mathrm{j}$ receives a solar irradiance $\mathrm{G}_{\mathrm{ij}}$.

Step 1: Transforming the original matrix into a data array $\mathrm{A}_{\mathrm{i}}$.

Step 2: Using the QuickSort [32], sorting of the $A_{i}$ data array in descending order.

Step 3: Create a matrix B of the same size as the matrix G.

Step 4: In turn, arrange the elements of array A into matrix B in the top-to-bottom direction, from left to right.

In order to explain the method, a numerical example is here given. Consider a solar PV system that includes 9 solar panels, SP connected, receiving different irradiance levels as in the table below.

Table 2. Starting configuration for numerical example

\begin{tabular}{|l|l|l|}
\hline 300 & 600 & 900 \\
\hline 600 & 900 & 1000 \\
\hline 900 & 1000 & 1000 \\
\hline
\end{tabular}

$G_{i j}$ corresponding to the value of solar irradiance in row $i$, column $j$. The $G_{i j}$ matrix is then changed into the following array A.

Table 3. Value array A for the starting configuration in table 2

\begin{tabular}{|l|l|l|l|l|l|l|l|l|}
\hline 300 & 600 & 900 & 600 & 900 & 1000 & 900 & 1000 & 1000 \\
\hline
\end{tabular}




\begin{tabular}{|l|l|l|l|l|l|l|l|l|}
\hline A0 & A1 & A2 & A3 & A4 & A5 & A6 & A7 & A8 \\
\hline
\end{tabular}

Using the QuickSort, the sorting of the A array in a descending order is carried out and the following array is obtained.

Table 4. Value array A after Quicksort for the starting configuration in table 3

\begin{tabular}{|c|c|c|c|c|c|c|c|c|}
\hline 1000 & 1000 & 1000 & 900 & 900 & 900 & 600 & 600 & 300 \\
\hline A0 & A1 & A2 & A3 & A4 & A5 & A6 & A7 & A8 \\
\hline
\end{tabular}

Finally the $B_{i j}$ matrix, with size of $3 \times 3$ similar to the original $G_{i j}$ matrix, is created arranging the elements of ordered A array into matrix B in the top-down direction, from left to right as described in Table IV.

Table 5. B matrix

\begin{tabular}{|l|l|l|}
\hline 1000 & 900 & 600 \\
\hline 1000 & 900 & 600 \\
\hline 1000 & 900 & 300 \\
\hline
\end{tabular}

Results of the simulation carried out using Matlab Simulink for this system are reported in the figures below.

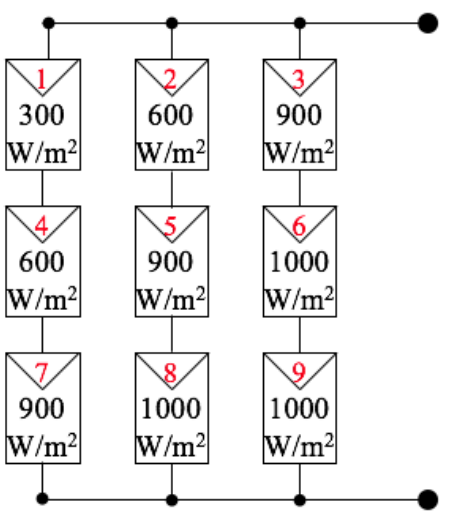

(a) SP connection circuit before reconfiguration

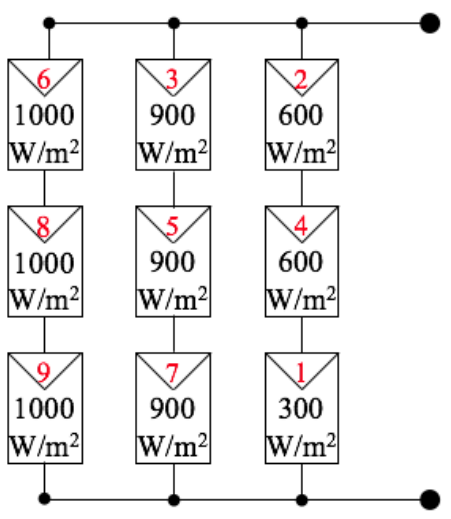

(c) SP connection circuit after reconfiguration 

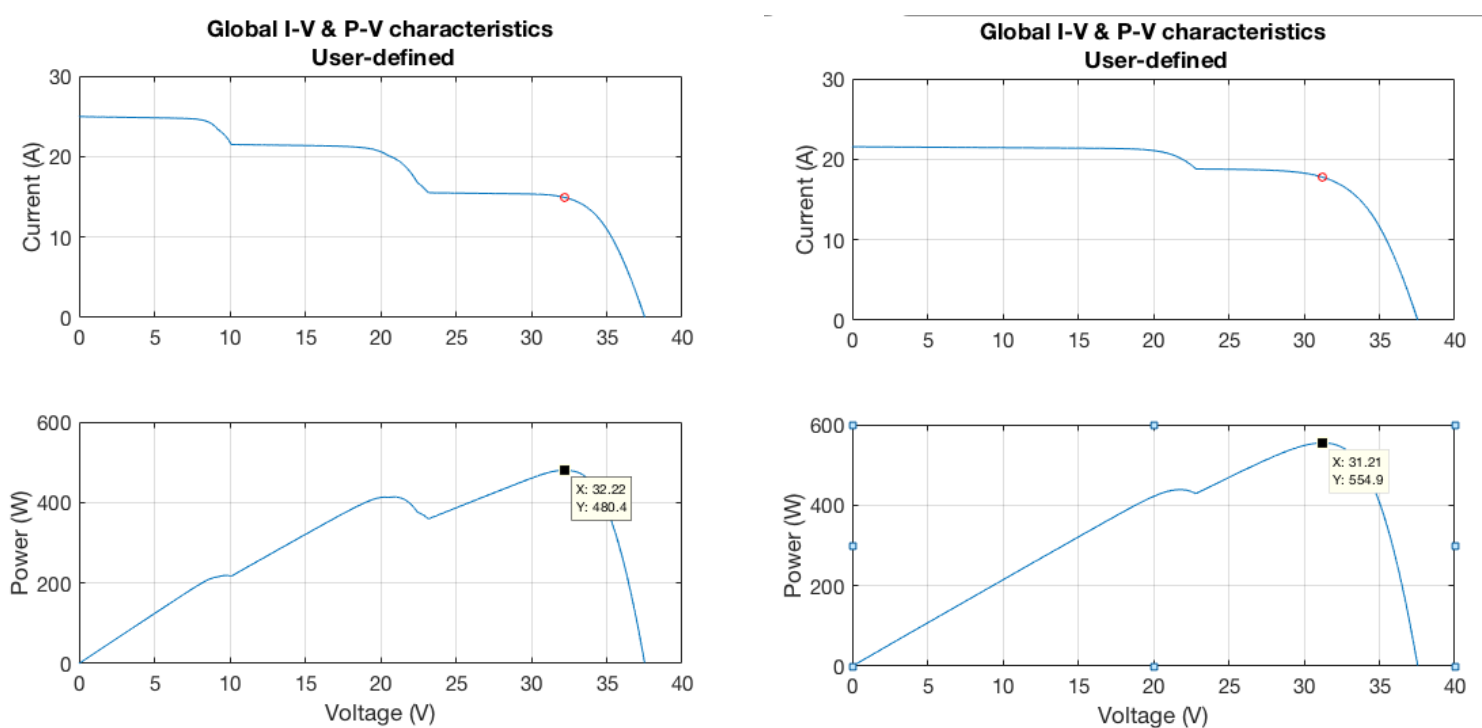

(b) PV system capacity before reconfiguration $\left(\mathrm{P}_{\mathrm{MPPT}}=480.4 \mathrm{~W}\right)$

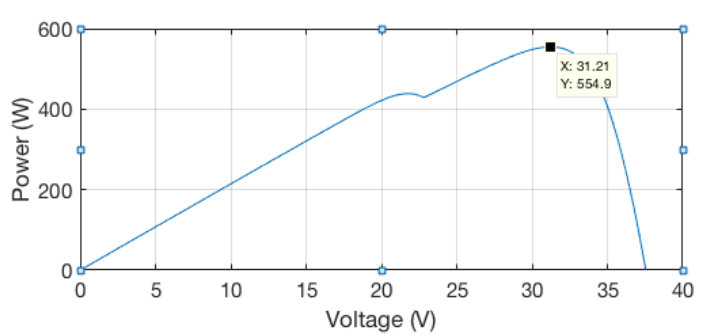

(d) PV System Capacity Chart after reconfiguration $\left(\mathrm{P}_{\mathrm{MPPT}}=\right.$ $554.9 \mathrm{~W}$

Fig 7. Simulation of the numerical example of the methodology for enhancing the efficiency of the SP connected PV plant, Fig. 7a,b show the original system with the $\mathrm{P}_{\mathrm{MPPT}}=480.4 \mathrm{~W}$, Fig. $7 \mathrm{c}, \mathrm{d}$ after reconfiguration with the $\mathrm{P}_{\mathrm{MPPT}}=554.9 \mathrm{~W}$

Figure 7 shows the comparison between the original system with an irradiance mismatch and the relevant P-V curve

\section{Experimental setup for SP reconfiguration algorithm}

The experimental part of this work has been carried out at the laboratory at the Institute of Energy Science- Vietnam Academy of Science and Technology, Hanoi Vietnam.

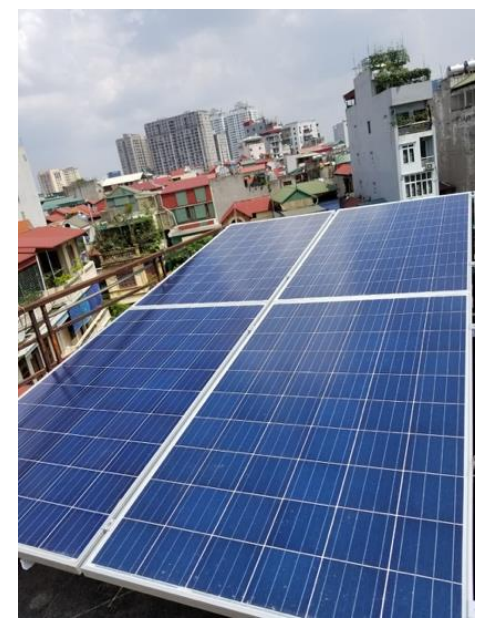

(a)

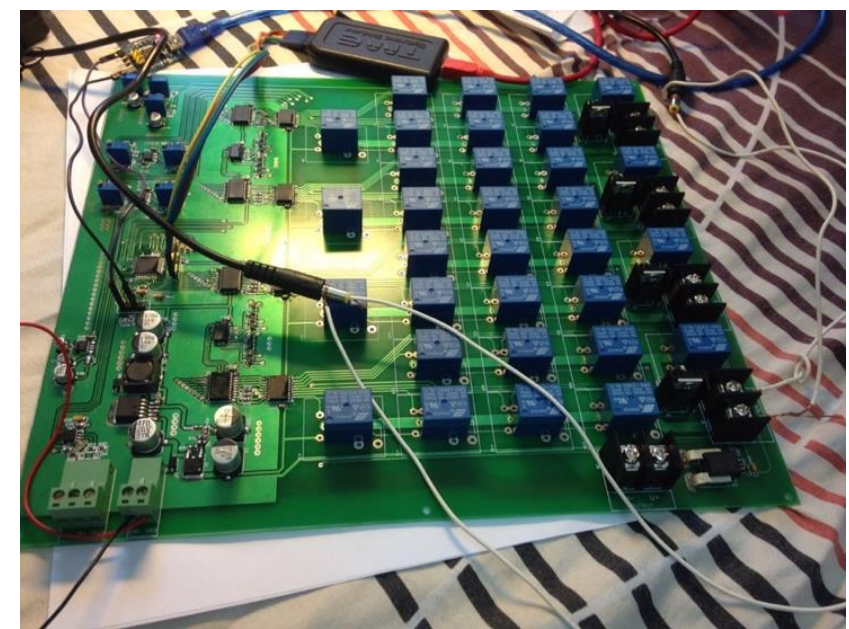

(b)

Fig 8. PV system with reconfigurator: a) PV panels; b) Switching matrix for SP topology

The experiment was applied to the $1 \mathrm{~kW}$ peak solar PV system, consisting of 4 panels type ET-P672270WB (Fig. 
8a), whose parameters are reported in Table 6.

Table 6. Electrical features of PV panels at $25^{\circ} \mathrm{C}$

\begin{tabular}{|c|c|c|c|c|}
\hline $\mathrm{V}_{\mathrm{MPP}}$ & $\mathrm{I}_{\mathrm{MPP}}$ & $\mathrm{P}_{\mathrm{MPP}}$ & $\mathrm{V}_{\mathrm{OC}}$ & $\mathrm{I}_{\mathrm{SC}}$ \\
\hline $36.4 \mathrm{~V}$ & $7.42 \mathrm{~A}$ & $270 \mathrm{~W}$ & $43.63 \mathrm{~V}$ & $7.9 \mathrm{~A}$ \\
\hline
\end{tabular}

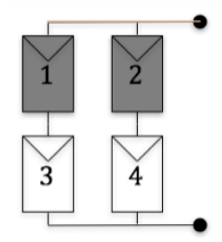

(a)

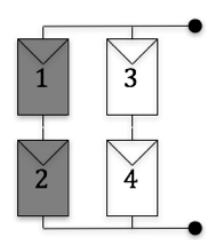

(b)

Fig 9. Connection of PV system before (a) and after (b) reconfiguration

The switching matrix for the SP topology is implemented as shown in Fig. 9 b. It consists of 4 current and voltage acquisition systems for the 4 panels; 1 current and voltage acquisition for output power of PV system; switching matrix (Fig. 4). The circuit connection for measurements is shown in Fig 10.

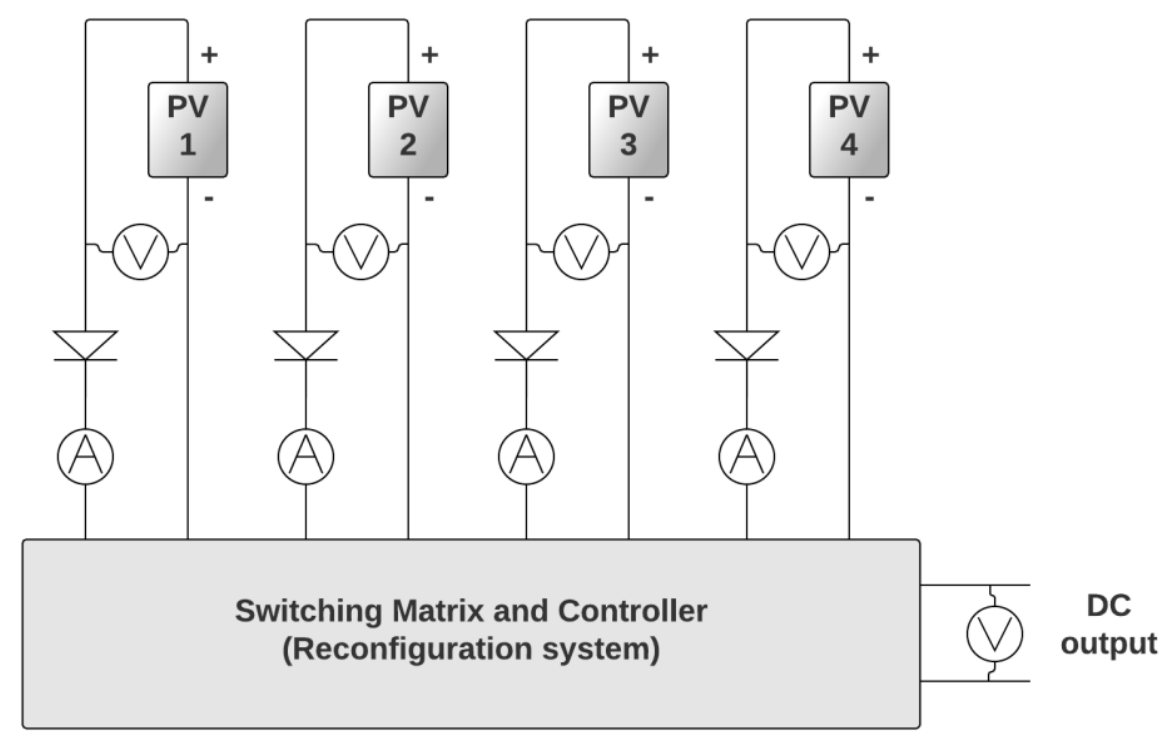

Fig 10. Diagram connection for measure current and voltage of each PV panel

In Fig 10, the method for measuring voltage online for each PV panel is shown. In this case, there is no need to disconnect the PV panels when measuring voltage. According to Fig 10, each PV panel needs a fixed diode connected in series before the switching matrix. Thus the voltage across each PV panel is measured directly online separately without the need to disconnect the PV panel from Switching matrix.

+ Disadvantage: Due to the diode connected, each pin looses a small amount of voltage across the diode (depending on semiconductor material and load current).

+ Advantages: Continuous monitoring, uninterruptible power supply; Durability of PV panel and components is 
improved, less noise that affects the quality of power because not continuous cutting the PV panel for measurements.

In automation mode, at each minute, the measuring system gets the voltage at each solar panel during the PV system normal operation. -

If voltage variation exceeds allowable limitation, the reconfiguration system will disconnect all PV panels, and then, measure current of each PV panel, the irradiance on each panel is calculated using (1). After that, the reconfiguration system shall automatically sent data to a PC (running an algorithm for finding the optimal configuration). In this case, the reconfiguration algorithm is run and the new configuration is implemented. If new configuration is different from the initial configuration, the PC sends the control data to the Switching matrix, and switches are controlled for changing the configuration from initial to the optimal one. Therefore if the system is shaded for a short time (below 1 minute) or shaded below the limitation, the reconfiguration system shall not operate. The efficiency of the reconfiguration system is then checked by shading each part of solar panels with various shading degrees chronologically. Output power is then measured and compared in case of reconfiguration system activation or not.

Solar power system with automatic reconfiguration system operated well as shown by the results reported in Table 7 and Fig. 10. In some cases the improvement in efficiency is of more than $43 \%$.

Table 7. Operation of reconfiguration system for optimal PV system in 11 cases of partial shading

\begin{tabular}{|c|c|c|c|c|c|c|c|c|c|c|}
\hline \multirow{2}{*}{ Case } & \multicolumn{4}{|c|}{ degree of partial shading $(\%)$} & \multicolumn{2}{|c|}{ Connection } & \multirow{2}{*}{$\begin{array}{c}\text { Number of } \\
\text { switching }\end{array}$} & \multicolumn{2}{|c|}{ Output power (W) } & \multirow{2}{*}{$\begin{array}{l}\text { Increasing } \\
\text { efficiency } \\
(\%)\end{array}$} \\
\hline & Panel 1 & Panel 2 & Panel 3 & Panel 4 & Initial & $\begin{array}{c}\text { after } \\
\text { reconfiguration }\end{array}$ & & Initial & $\begin{array}{c}\text { after } \\
\text { reconfiguration }\end{array}$ & \\
\hline 1 & 0 & 0 & 0 & 0 & $\{1-3\} \|\{2-4\}$ & $\{1-3\} \|\{2-4\}$ & 0 & 1080 & 1080 & 0.00 \\
\hline 2 & 10 & 10 & 10 & 0 & $\{1-3\} \|\{2-4\}$ & $\{1-3\} \|\{2-4\}$ & 0 & 987.9 & 987.9 & 0.00 \\
\hline 3 & 20 & 20 & 0 & 10 & $\{1-3\} \|\{2-4\}$ & $\{1-2\} \|\{3-4\}$ & 2 & 907.6 & 971.8 & 7.07 \\
\hline 4 & 30 & 30 & 10 & 0 & $\{1-3\} \|\{2-4\}$ & $\{1-2\} \|\{3-4\}$ & 2 & 798.7 & 878.8 & 10.03 \\
\hline 5 & 40 & 30 & 20 & 10 & $\{1-3\} \|\{2-4\}$ & $\{1-2\} \|\{3-4\}$ & 2 & 738.9 & 783.3 & 6.01 \\
\hline 6 & 50 & 40 & 30 & 40 & $\{1-3\} \|\{2-4\}$ & $\{1-2\} \|\{3-4\}$ & 2 & 604.7 & 616.2 & 1.90 \\
\hline 7 & 50 & 50 & 50 & 50 & $\{1-3\} \|\{2-4\}$ & $\{1-3\} \|\{2-4\}$ & 0 & 535.2 & 535.2 & 0.00 \\
\hline 8 & 60 & 60 & 0 & 0 & $\{1-3\} \|\{2-4\}$ & $\{1-2\} \|\{3-4\}$ & 2 & 529.7 & 752.5 & 42.06 \\
\hline 9 & 65 & 65 & 15 & 15 & $\{1-3\} \|\{2-4\}$ & $\{1-2\} \|\{3-4\}$ & 2 & 450 & 643.7 & 43.04 \\
\hline 10 & 75 & 75 & 30 & 30 & $\{1-3\} \|\{2-4\}$ & $\{1-2\} \|\{3-4\}$ & 2 & 369.8 & 507.1 & 37.13 \\
\hline 11 & 50 & 60 & 60 & 40 & $\{1-3\} \|\{2-4\}$ & $\{1-2\} \|\{3-4\}$ & 2 & 450.9 & 504 & 39.29 \\
\hline
\end{tabular}

In Table 7, the configuration $\{1-3\} \|\{2-4\}$ corresponds to the connections depicted in Fig.9(a). 


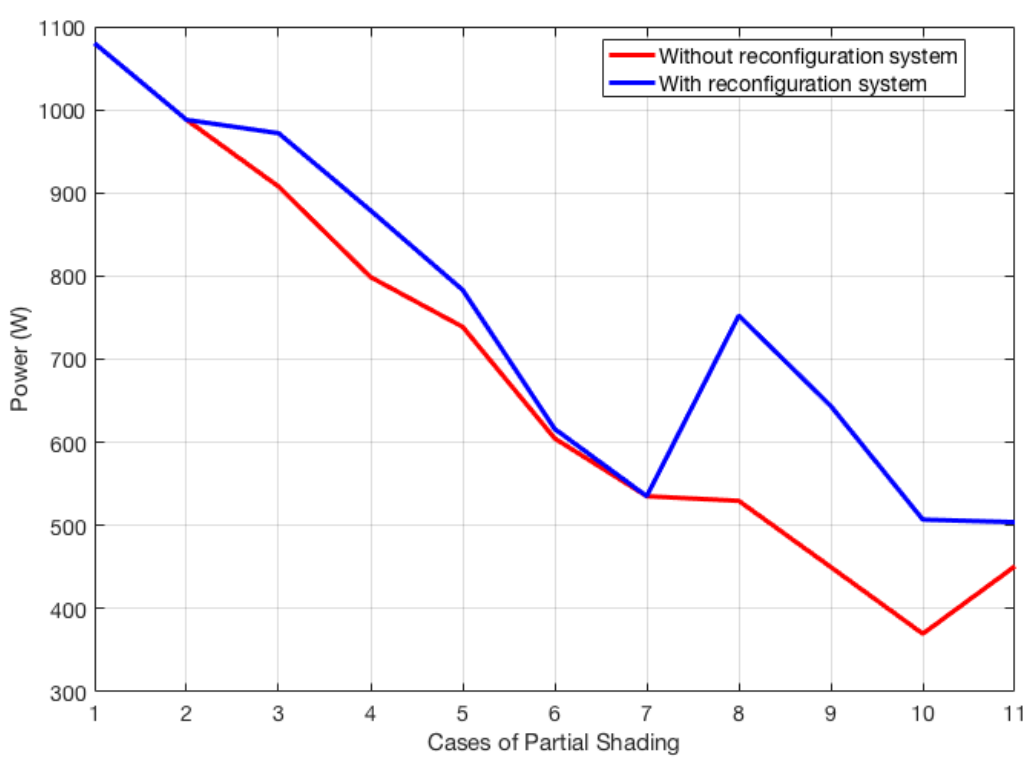

Fig 5. Diagram comparing the output power of the solar power system with the reconfiguration system and without reconfiguration system when in partial shading situations

Figure 11 shows the improvements implementing the reconfiguration system for all the possible shadings reported in Table 7.

\section{Application of reconfiguration strategy for a large PV system}

In [33], the authors propose a reconfiguration method for TCT topology, applied to a large PV system. The proposed reconfiguration method divides the PV panels into two groups, the Fixed Part and the Reconfigurable Part. The advantage of the method is the reduction of the number of switches in the switching matrix, depending on the number of PV panels in Reconfigurable Part. The biggest disadvantage of the proposed method is that it is not possible to rearrange all PV panels. Indeed only the connection of PV panels in the Reconfigurable Part can be changed, so in many cases the reconfiguration system will not be able to operate effectively. For example, a situation of partial shading on the Fixed Part which cannot be improved using reconfiguration is shown in Figure 12.

In this paper, we propose a reconfiguration method for larger PV systems, which could rearrange the position of all the PV panels while minimizing the number of switches. 


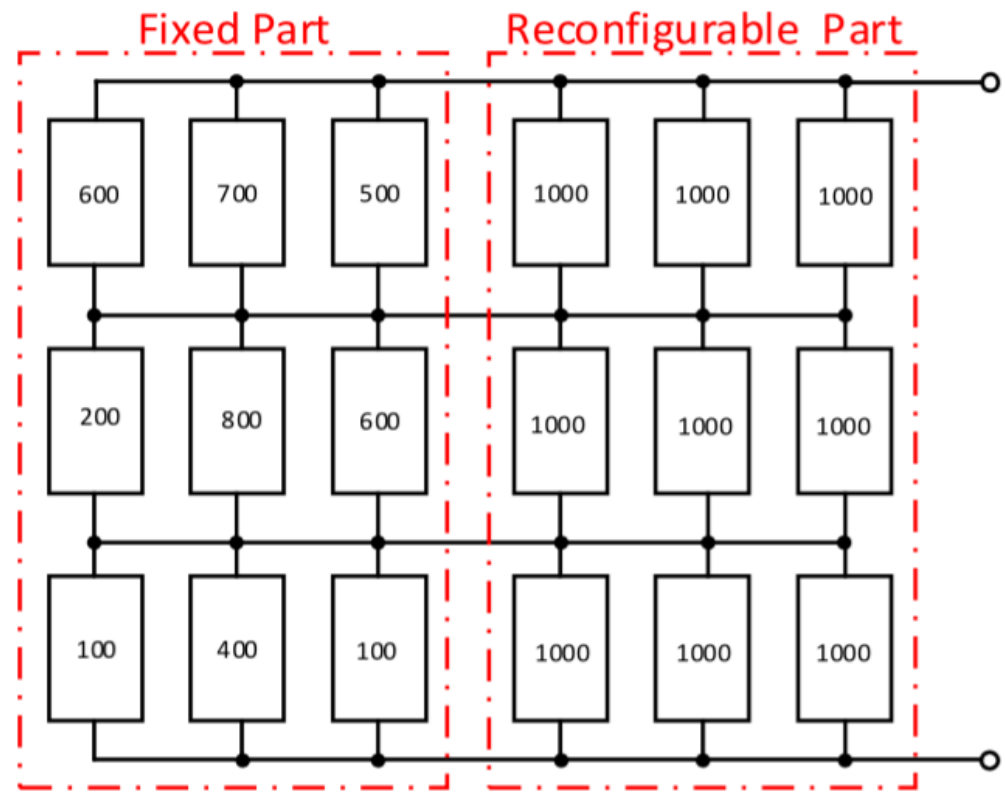

\subsection{System design}

The biggest problem of reconfiguration methods for TCT and SP topologies is the size of the switching matrix. [22-24]. The number of switches is at least $N x K x M$ where $N$ is the number of PV panels, $K$ is number of switches for each PV panel (in TCT: $K=2$ and in SP: $K=3$ ), $M$ is maximum number of PV panels to connect in series.

In order to minimize the cost of the proposed system, the authors recommend a method for splitting the groups of PV panels using the TCT connection structure. In this way, the TCT connection groups the SP connected panels. The reconfiguration strategy is applied to the TCT and SP connection circuits to increase the local performance of each group, thereby increasing the overall system performance.

Consider a 14.4kW peak solar PV plant consisting of 60 PV panels Schüco International KG MPE 240 PS 04. The rating of each panel is reported in Table 8.

The inverter used for this plant is a SUNNY TRIPOWER 15000TL whose rated values are reported in table 9. Peak power of the system is $14.4 \mathrm{~kW}$.

Table 8. Electrical Characteristics of Schüco International KG MPE 240 PS 04

\begin{tabular}{|c|c|c|c|c|}
\hline $\mathrm{V}_{\mathrm{MPP}}$ & $\mathrm{I}_{\mathrm{MPP}}$ & $\mathrm{P}_{\mathrm{MPP}}$ & $\mathrm{V}_{\mathrm{OC}}$ & $\mathrm{I}_{\mathrm{SC}}$ \\
\hline $30.4 \mathrm{~V}$ & $7.91 \mathrm{~A}$ & $240 \mathrm{~W}$ & $37 \mathrm{~V}$ & $8.61 \mathrm{~A}$ \\
\hline
\end{tabular}

Table 9. Electrical Characteristics of SUNNY TRIPOWER 15000TL

\begin{tabular}{|l|l|}
\hline Technical Data & Sunny Tripower 15000TL \\
\hline Max. DC power / DC rated power & $15340 \mathrm{~W} / 15340 \mathrm{~W}$ \\
\hline Max. input voltage & $1000 \mathrm{~V}$ \\
\hline MPP Voltage range/rated input voltage & $360 \mathrm{~V}$ to $800 \mathrm{~V} / 600 \mathrm{~V}$ \\
\hline Min. input voltage / initial input voltage & $150 \mathrm{~V} / 188 \mathrm{~V}$ \\
\hline
\end{tabular}




\begin{tabular}{|l|l|}
\hline Max. input current input A / input B1 & $33 \mathrm{~A} / 11 \mathrm{~A}$ \\
\hline Max. input current per string input A1 / input B1 & $40 \mathrm{~A} / 12.5 \mathrm{~A}$ \\
\hline Max. DC short-circuit current input A / input B & $50 \mathrm{~A} / 17 \mathrm{~A}$ \\
\hline Number of independent MPP inputs/strings per MPP input & 2 / A:5;B:1 \\
\hline
\end{tabular}

Instead of developing the system with a basic connection, the authors propose the construction of a $60 \mathrm{PV}$ panels system connected to 6 groups, each with 10 PV panels using SP topology. 6 groups connected in TCT topology. The output of the TCT circuit connected to the SUNNY TRIPOWER 15000TL inverter as shown in Fig. 13.

The switching matrix design for the system:

- $\quad$ Each group in SP topology: 150 relays.

- 6 groups connected in TCT topology: 78 relays.

Total number of relays: $150 * 6+78=978$ relays.

Table 10. Electrical Characteristics of PV plant

\begin{tabular}{|l|l|}
\hline Number of modules $\mathrm{n}$. & 60 \\
\hline Rated power $\mathrm{W}_{\mathrm{P}}$ & $14.400 \mathrm{~W}$ \\
\hline Rated voltage at STC (Standard Test Conditions) $\mathrm{V}_{\max }$ & $456 \mathrm{~V}$ \\
\hline Maximum output power current $\mathrm{I}_{\max }$ & $31,64 \mathrm{~A}$ \\
\hline Open circuit voltage $\mathrm{V}_{\mathrm{oc}}$ & $555 \mathrm{~V}$ \\
\hline Short Circuit current $\mathrm{I}_{\mathrm{sc}}$ & $34.44 \mathrm{~A}$ \\
\hline
\end{tabular}

3-phase Inverters SMA Solar Technology AG, Sunny Tripower 15000TL PWM forced commutation, with MPPT algorithm. The inverters will be parallel connected at the outputs

Input Voltage of the DC/AC inverter: 456V 


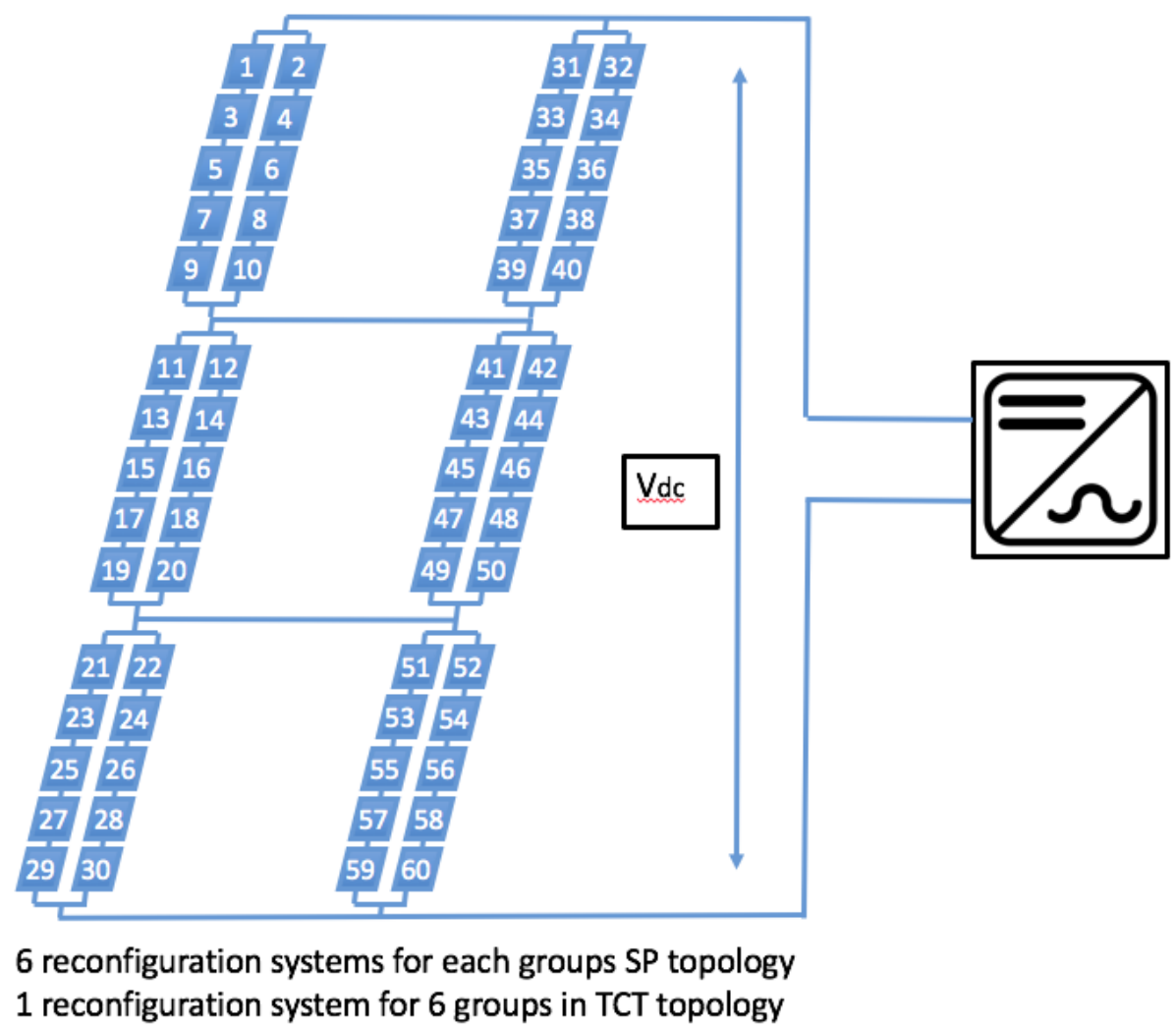

Fig 7. Subgroup design diagram of PV system.

The PV system includes $60 \mathrm{PV}$ panels, divided into 6 groups, each group composed of 10 panels connected in SP topology as in table 11. Each group is connected to a lower level reconfiguration system for SP topology, whose switching matrix is described in section 3. In each group, panels can be put in different positions, but the number of panels per string is fixed to 5 .

Table 11. Groups of PV panels in SP topology

\begin{tabular}{|c|c|c|c|c|c|}
\hline Group 1 & Group 2 & Group 3 & Group 4 & Group 5 & Group 6 \\
\hline$\{1,2, \ldots, 10\}$ & $\{11,12, \ldots, 20\}$ & $\{21,22, \ldots, 30\}$ & $\{31,32, \ldots, 40\}$ & $\{41,42, \ldots, 50\}$ & $\{51,52, \ldots, 60\}$ \\
\hline
\end{tabular}

The reconfiguration algorithm within each group of $10 \mathrm{PV}$ panels was described in section 4 . With the described reconfiguration system, each group of solar panels gives the maximum output. The output of each group is of course in DC. 


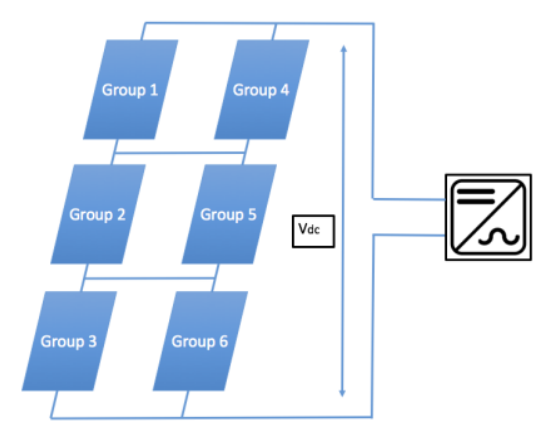

Fig 8. 6 subgroups connected in TCT topology

At the higher hierarchical level, a TCT reconfigurator manages the 6 groups (Fig 14) as described in section 2.1.

The advantages of a system that uses a hierarchical reconfiguration, as compared to a conventional system, are listed below:

- During the operation, when the system is partially shaded, always reconfigure to increase the performance of the system.

- In cases, especially low light, when 3 groups of serial connected SP topology do not meet the input voltage for the inverter $(<360 \mathrm{~V})$, the TCT may serially connects more SP groups to meet the input voltage requirement of the inverter $(>360 \mathrm{~V})$.

At each minute, the reconfiguration system for SP topology work within each group. Current and voltage are measured and based on the voltage difference measured across the panels, the automation is triggered or not. Then the connections of each group to the optimal configuration are changed if necessary.

If at least two groups change the connections within different rows, the Reconfiguration for TCT topology will start, based on the sum of irradiances calculated in each group and change the initial connection into the optimal one if necessary.

The important constraint is that the output voltage of the PV system must be within the input range of the inverter.

\subsection{Matlab simulation}

As an example a simulation was made in Matlab environment and results are reported in Fig 15a. In this case, the clouds are shadowing the PV system from bottom to top. The initial condition is depicted in fig. 15a. The number in the boxes indicating the real irradiance in $\mathrm{W} / \mathrm{m}^{2}$. 


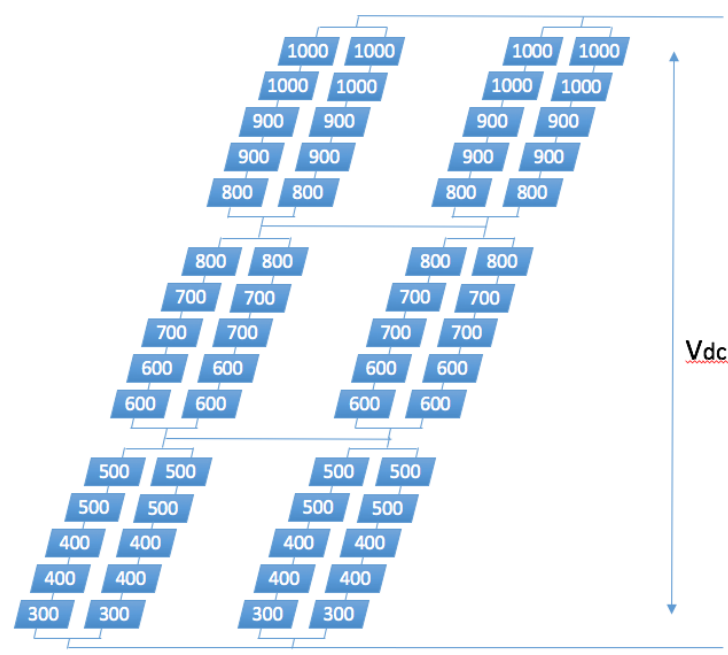

(a)
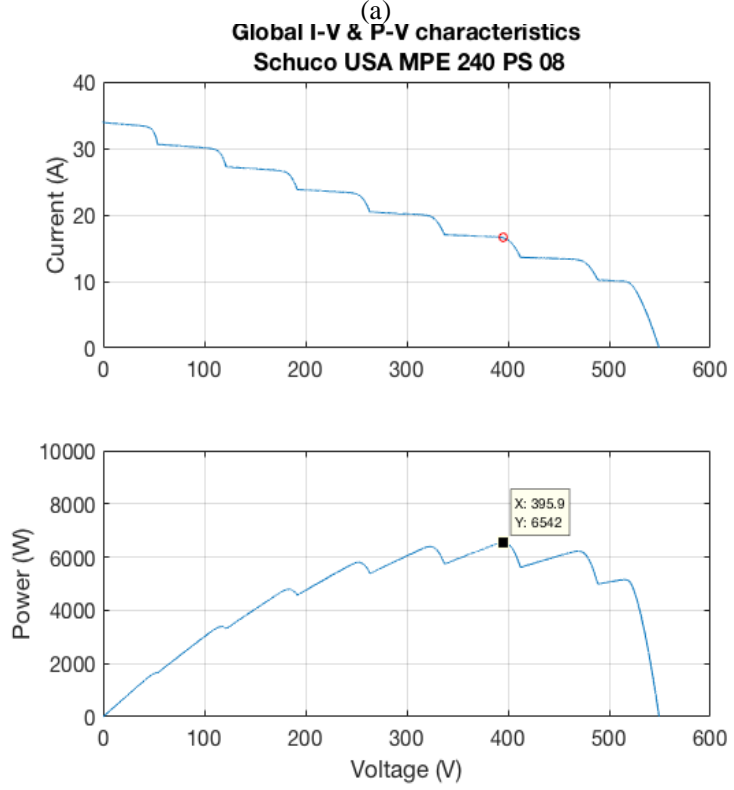

(b)

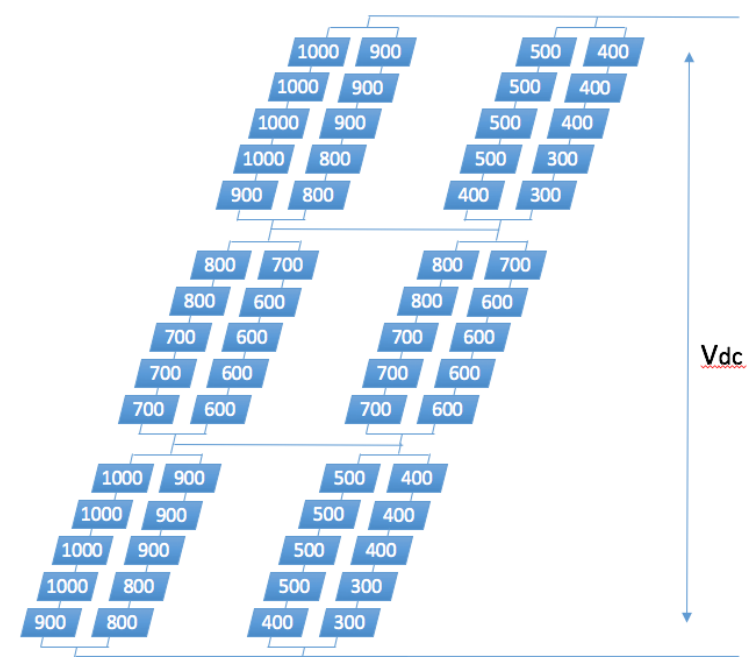

(c)
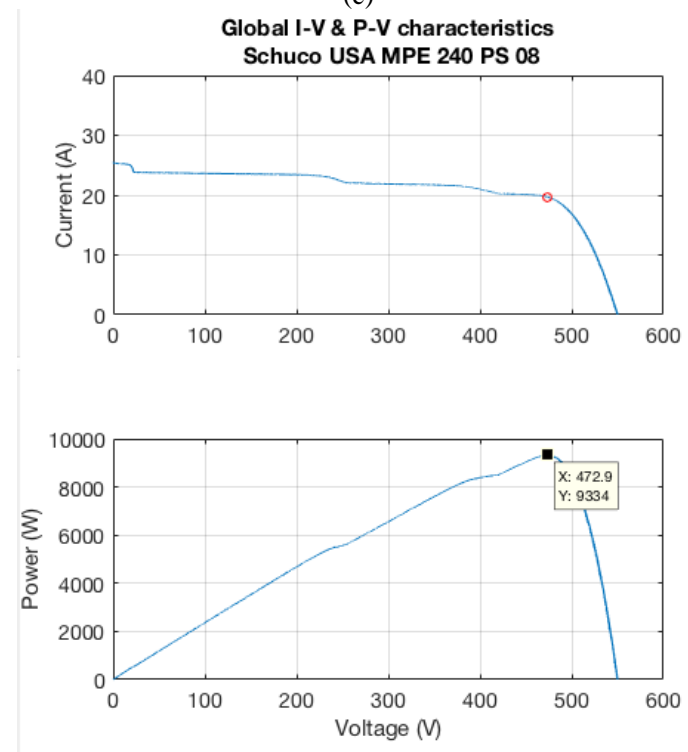

(d)

Fig 15. Diagram comparing the output power of the solar power system with (a) the reconfiguration system $P_{\max }=9334 \mathrm{~W}$ and without (b) reconfiguration system $\mathrm{P}_{\max }=6542 \mathrm{~W}$ when in PS situations

As a result the lower level reconfigurator starts in each group; the reconfiguration system for SP topology optimizes 345 the output power of each group as depicted in Fig 16.

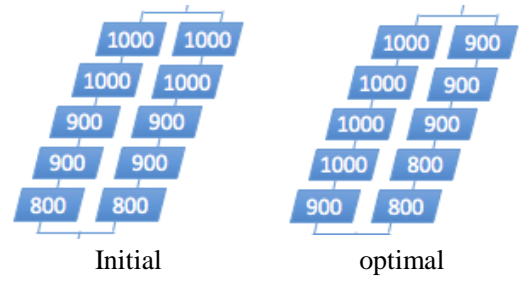

Group 1,4

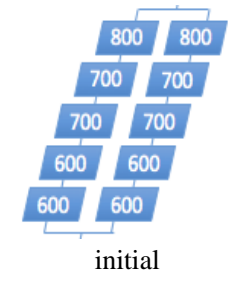

Group 2,5
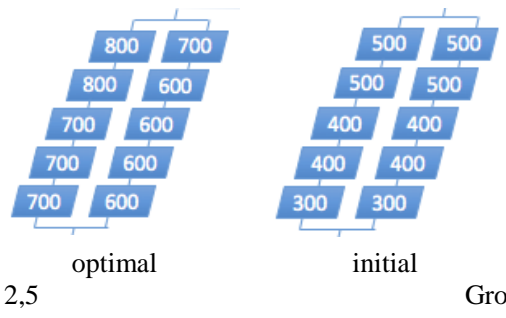

Group 3,6

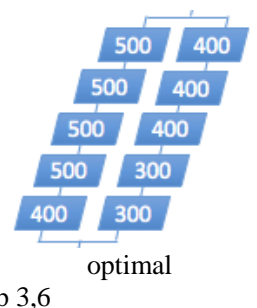


The higher hierarchical level reconfigurator starts as more than two groups have changed their configuration at the lower level. Therefore, the reconfiguration system for TCT topology optimizes the output power of the overall system as depicted in Fig 17 (where irradiances are indicated as the sum of the irradiances of the panels within the group).

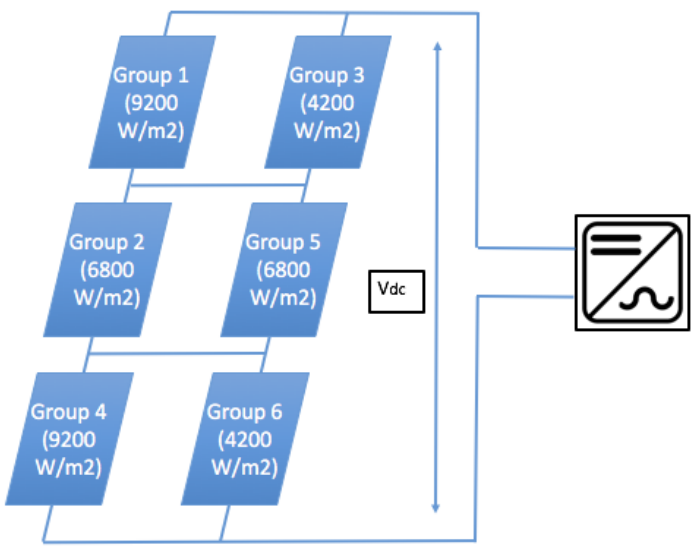

Fig 17. Optimal configuration of groups in TCT topology.

After changing the connection of the PV system's panels, the system increased the performance from 6542W (Fig 15b) to $9334 \mathrm{~W}$ (Fig 15d), increasing the system's performance by $42.67 \%$.

\subsection{Comparison with fully reconfigurable systems}

In a fully controllable Switching matrix design for $60 \mathrm{PV}$ panels in SP topology, $30 \mathrm{PV}$ panels can be series connected. In cases, with strong shading or low irradiation, when 3 groups of serial connected SP topology do not meet the input voltage for the inverter $(<360 \mathrm{~V})$, the TCT can serially connect more SP groups to meet the input voltage requirement of the inverter $(>360 \mathrm{~V})$. In this case, it is needed to design a Switching matrix with $60 * 3 * 30=5400$ relays. With the same case in section 5.1, using the Matlab simulink framework, we have the result in Fig 18.

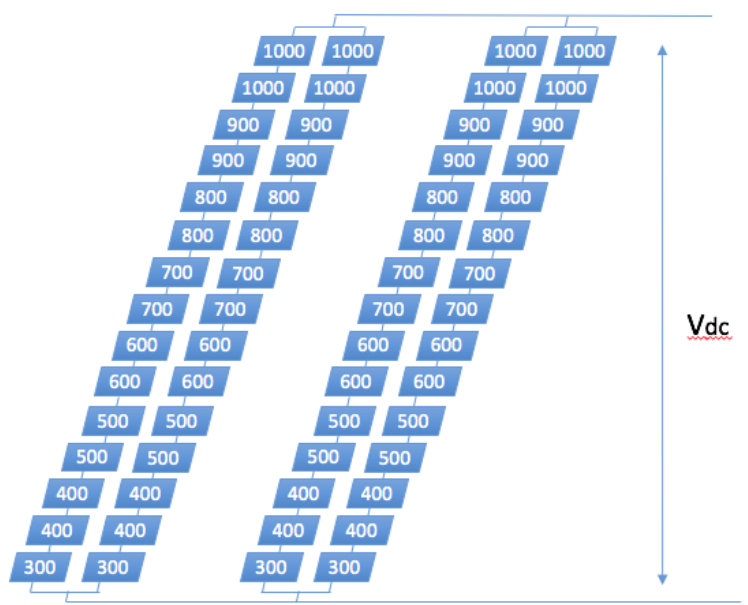

(a)

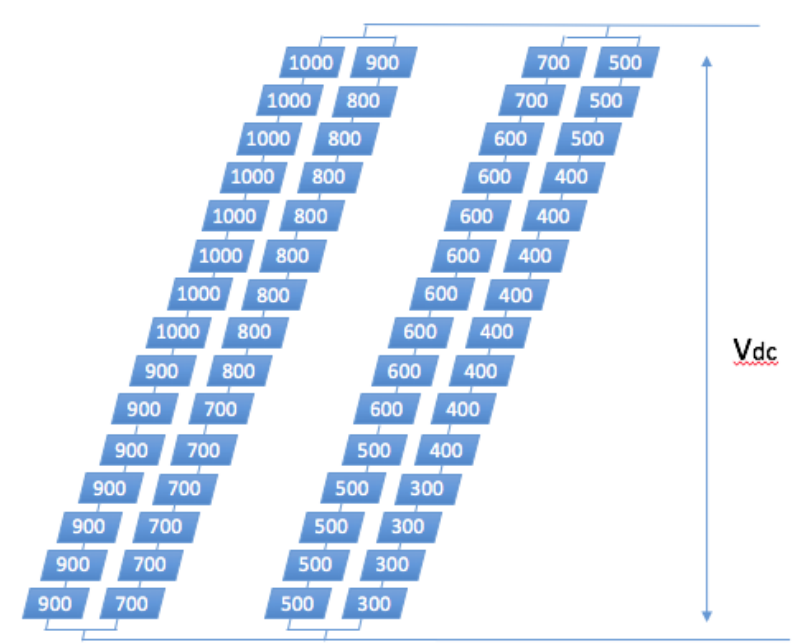

(c) 

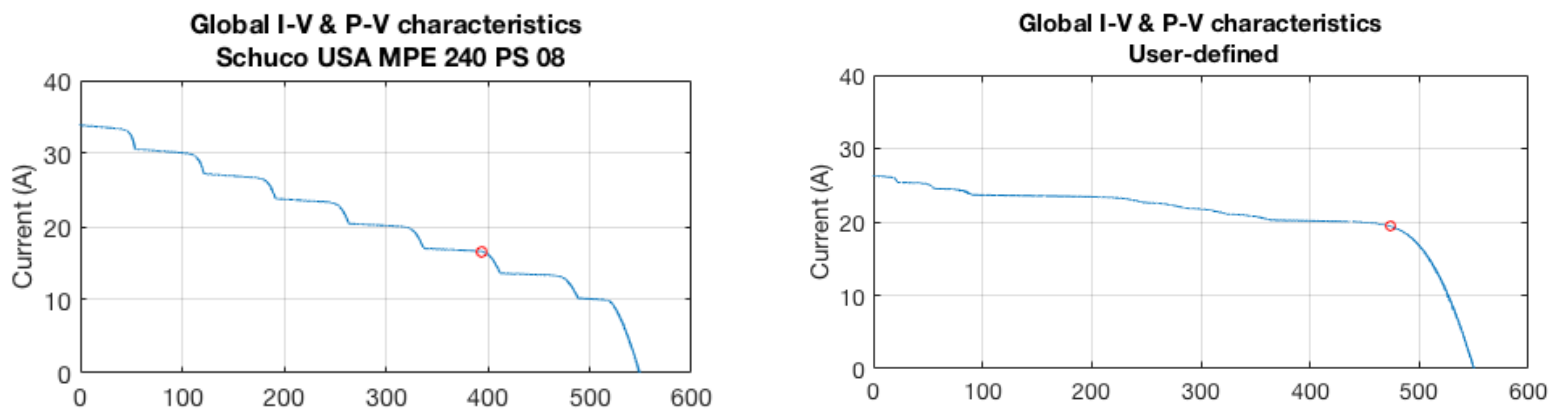

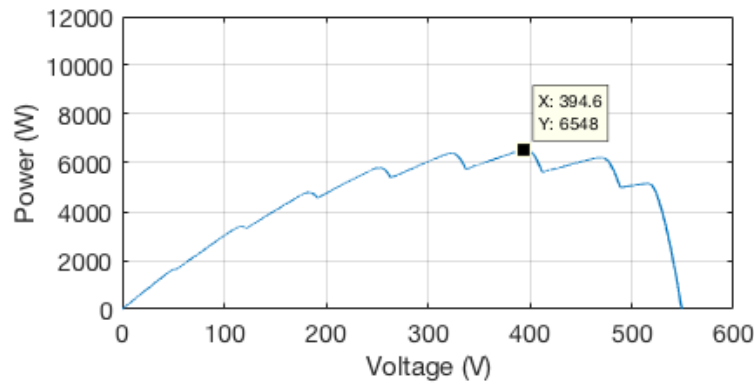

(b)

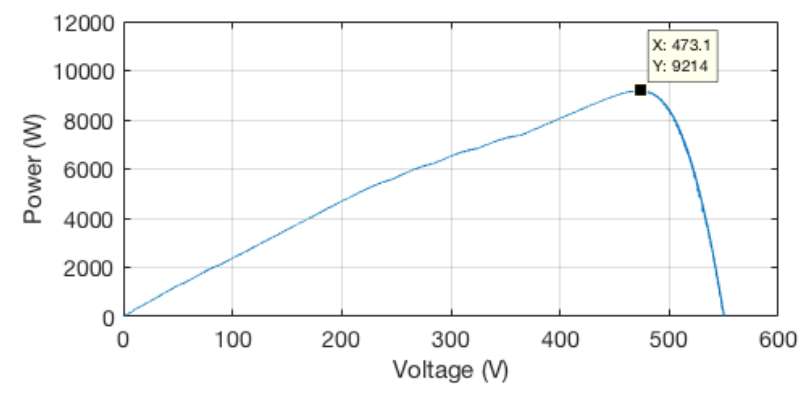

(d)

Fig 9. Diagram comparing the output power of the solar power system with fully controllable Switching matrix in SP topology

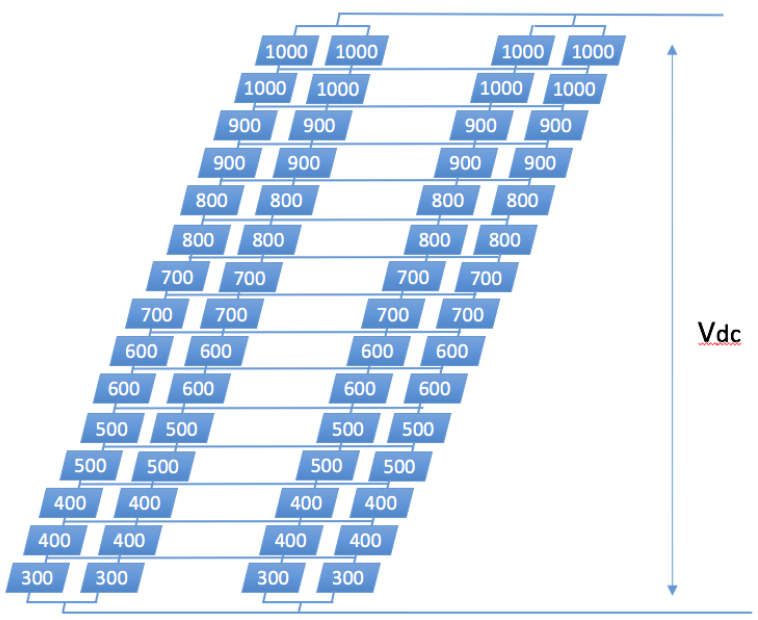

(a)

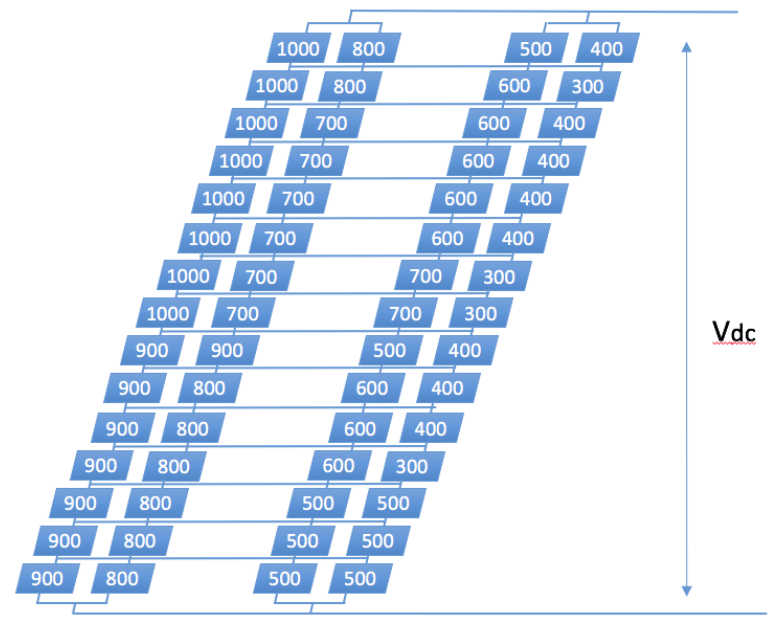

(c) 

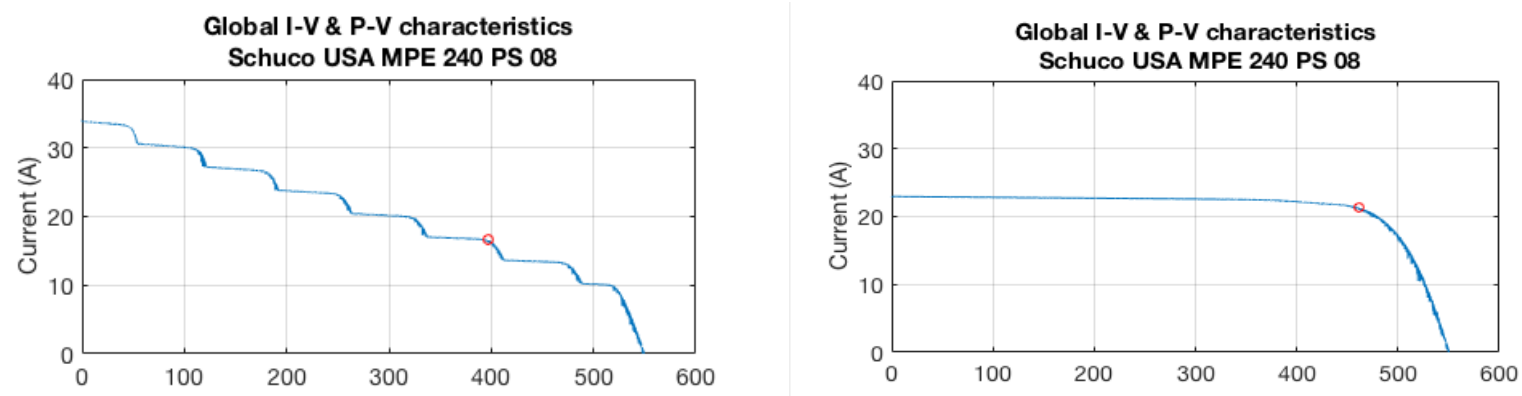

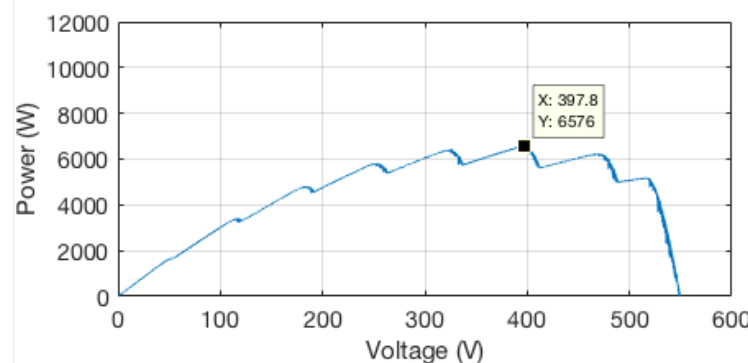

(b)

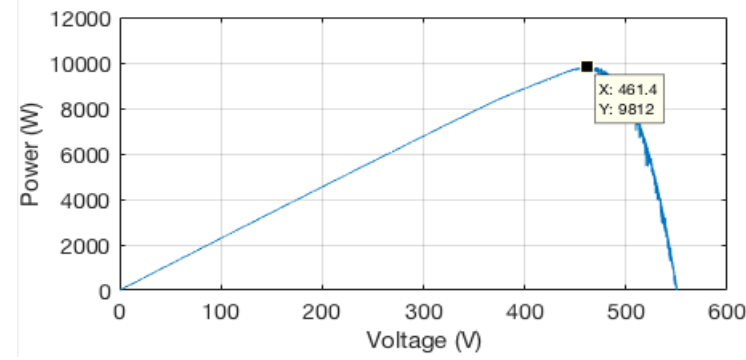

(d)

Fig. 19. Diagram comparing the output power of the solar power system with fully controllable Switching matrix in TCT topology

As you can see in Fig 19b, before reconfiguration, output power of PV system $\mathrm{P}_{\mathrm{MPPT}}$ is $6548 \mathrm{~W}$, after reconfiguration $\mathrm{P}_{\text {MPPT }}$ is $9214 \mathrm{~W}$. In this case, the output is smaller than the one in hierarchical topology (in Fig $16 \mathrm{~d}$ is $\mathrm{P}_{\mathrm{MPPT}}=9334 \mathrm{~W}$ ). Indeed in general TCT connection offers a larger power output and the PV system in hierarchical topology uses both SP topology and TCT topology.

The comparison is shown in Table 12.

Table 12. Comparison

\begin{tabular}{|l|c|c|c|}
\hline \multirow{2}{*}{ Reconfiguration Method } & \multirow{2}{*}{ Number of Relays } & \multicolumn{2}{c|}{ PMPP $(\mathbf{W})$} \\
\cline { 3 - 4 } & & $\begin{array}{c}\text { Before } \\
\text { reconfiguration }\end{array}$ & $\begin{array}{c}\text { After } \\
\text { reconfiguration }\end{array}$ \\
\hline Hierarchical topology & 978 & 6542 & 9334 \\
\hline Full reconfiguration in TCT topology & 3630 & 6576 & 9812 \\
\hline Full reconfiguration in SP topology & 5400 & 6548 & 9214 \\
\hline
\end{tabular}

As it can be observed the output power considering the hierarchical topology is only $4.87 \%$ lesser as compared to a full reconfiguration TCT for this case, but the number of switches is much smaller.

The shadowing case here considered can be retained as the most meaningful situation. Since shadowing from left to right and vice versa would not be a significant case for reconfiguration, especially if shadowing affects all panels in one series connected row. Other cases with shadowing in diagonal can still be easily re-conducted to the case here studied. The convenience of such reconfiguration techniques can be assessed by considering the economic benefits [34-36]. 


\section{Conclusion}

In recent research publications, to cope with the problem of mismatch in small PV fields, the authors proposed a solution to improve the performance of solar energy systems based on reconfiguration using a Total-Cross-Tied topology (TCT) [22-24]. In this study, the authors propose a solution for improving the efficiency of solar-powered systems using the SP configuration (Series-Parallel topology) as basic topology. The latter is more common in existing PV generators. To solve the reconfiguration problem over SP-based PV systems, the proposed author's solution consists of two main parts: a Switching matrix and QuickSort method to find the optimal connection configuration for the SP connection. The method uses the QuickSort with the complexity On (logn) which allows for application in large solar energy systems. In addition, the authors propose a new hierarchical architecture to limit the number of switches in reconfigurable systems and at the same time provide a solution for larger PV fields. PV panels are grouped into SPbased smaller units at the lower level. Inside each group the proposed SP-based optimal reconfiguration is carried out. While at the higher level, the groups are considered as single entities and a TCT based topology supports the reconfiguration of the groups of panels. An experimental application shows the efficiency of the SP based reconfiguration used for the lower level, while a simulation demonstrates the practical applicability of the whole hierarchical optimal reconfiguration strategy proposed by the authors.

\section{Acknowledgements}

The authors especially thank the IES - VAST for providing fund and creating favour in carrying out experimental part of this work during the implementation of the study. This paper is developed as a subsidiary component of the study "Study on methodology and building device increasing efficiency of photovoltaic systems under nonhomogeneous solar irradiation" Code DL0000.01/18-19.

\section{References}

1. Trends in photovoltaic applications. Survey report of selected IEA countries between 1992 and 2012. 2013: International Energy Agency.

2. Electricity from sunlight: an introduction to photovoltaics. Choice: Current Reviews for Academic Libraries, 2011. 48(5): p. 933-933.

3. M. Veerachary; T. Senjyu ; K. Uezato, Voltage-based maximum power point tracking control of PV system. IEEE Transactions on Aerospace and Electronic Systems, Jan 2002. 38(1): p. 262 - 270.

4. Alireza Kouchaki, Hossein Iman-Eini., Behzad Asaei, A new maximum power point tracking strategy for PV arrays under uniform and non-uniform insolation conditions. Solar Energy, 2013. 91: p. 221-232.

5. Marco Balato, Luigi Costanzo, Massimo Vitelli, Maximum Power Point Tracking Techniques. Wiley Encyclopedia of Electrical and Electronics Engineering, 2016: p. 1-26.

6. Yi-Hua Liu, Jing-Hsiao Chen, Jia-Wei Huang, Global maximum power point tracking algorithm for PV systems operating under partially shaded conditions using the segmentation search method. Solar Energy, 2014. 103: p. 350-363.

7. Jian Zhao, Xuesong Zhou, Youjie Mab, Wei Liu, A novel maximum power point tracking strategy based on optimal voltage control for photovoltaic systems under variable environmental conditions. Solar Energy, 2015. 122: p. 640-649.

8. Po-Cheng Chen, Po-Yen Chen, Yi-Hua Liu, Jing-Hsiao Chen, Yi-Feng Luo,, A comparative study on maximum power point tracking techniques for photovoltaic generation systems operating under fast changing environments. Solar Energy, 2015. 119: p. 261-276.

9. Fan Zhang, Jon Maddy, Giuliano Premier, Alan Guwy, Novel current sensing photovoltaic maximum power point tracking based on sliding mode control strategy. Solar Energy, 2015. 118: p. 80-86.

10. Salimi, M., Practical implementation of the Lyapunov based nonlinear controller in DC-DC boost converter 
for MPPT of the PV systems. Solar Energy. 173: p. 246-255.

11. Youssef Cheddadi, Fatima Errahimi, Najia Es-sbai,, Design and verification of photovoltaic MPPT algorithm as an automotive-based embedded software. Solar Energy, 1 September 2018. 171(414-425).

12. Mazen Abdel-Salam, Mohamed-Tharwat El-Mohandes, Mohamed Goda, An improved perturb-and-observe based MPPT method for PV systems under varying irradiation levels. Solar Energy, 1 September 2018. 171: p. 547-561.

13. Nicola Femia, Giovanni Petrone, Giovanni Spagnuolo, Massimo Vitelli, Power Electronics and Control Techniques for Maximum Energy Harvesting in Photovoltaic systems. 2012 CRC Press Published, December 18,2012, ISBN 9781466506909.

14. P.G. McCormick, H. Suehrcke, The effect of intermittent solar radiation on the performance of PV systems. Solar Energy, 1 September 2018. 171: p. 667-674.

15. Achim Woyte, Johan Nijs, Ronnie Belmans, Partial shadowing of photovoltaic arrays with different system configurations: literature review and field test results. Solar Energy, 2003. 74: p. 17.

16. M. Z. Shams El-Dein ; Mehrdad Kazerani ; M. M. A. Salama, Optimal Photovoltaic Array Reconfiguration to Reduce Partial Shading Losses. IEEE TRANSACTIONS ON SUSTAINABLE ENERGY, 2012. 4(1): p. 9.

17. Damiano La Manna, Vincenzo LiVigni, Eleonora Riva Sanseverino, Vincenzo Di Dio, Pietro Romano, Reconfigurable electrical interconnection strategies for photovoltaic arrays: A review. Renewable and Sustainable Energy Reviews, 2014.

18. Mohammadreza Akrami, Kazem Pourhossein, A novel reconfiguration procedure to extract maximum power from partially-shaded photovoltaic arrays. Solar Energy, October 2018. 173: p. 110-119.

19. Anurag Singh Yadav, V. Mukherjee, Line losses reduction techniques in puzzled PV array configuration under different shading conditions. Solar Energy, 1 September 2018. 171: p. 774-783.

20. Manjunath Matam, Venugopal Reddy Barry, Avinash Reddy Govind, Optimized Reconfigurable PV array based Photovoltaic water-pumping system. Solar Energy, August 2018. 170: p. 1063-1073.

21. Majid Horoufiany, Reza Ghandehari, Optimization of the Sudoku based reconfiguration technique for PV arrays power enhancement under mutual shading conditions. Solar Energy, 1 January 2018. 159: p. 1037 1046.

22. Eleonora Riva Sanseverino, Thanh Ngo Ngoc, Marzia Cardinale, Vincenzo Li Vigni, Domenico Musso, Pietro Romano, Fabio Viola, Dynamic programming and Munkres algorithm for Optimal Photovoltaic Arrays Reconfiguration. Solar Energy, 12/2015. 122: p. Pages 347-358.

23. Ngo Ngoc Thanh, Quang Nguyen Phung, Pham Thuong Cat, Improved control algorithm for increase efficiency of photovoltaic system under non-homogeneous solar irradiance. Special issue control and automation, 2016. 16: p. 12.

24. Thanh Ngo Ngoc, Quang Nguyen Phung., Linh Nguyen Tung, Eleonora Riva Sanseverino, Pietro Romano, Fabio Viola, Increasing efficiency of photovoltaic systems under non-homogeneous solar irradiation using improved Dynamic Programming methods. Solar Energy, 2017. 150: p. 325-334.

25. W. Herrmann, W. Wiesner, W. Vaassen, Hot spot investigations on PV modules-new concepts for a test standard and consequences for module design with respect to bypass diodes. Photovoltaic specialists conference, 1997., conference record of the twenty-sixth IEEE, 1997.

26. B. Patnaik ; P. Sharma ; E. Trimurthulu ; S. P. Duttagupta ; V. Agarwal, Reconfiguration strategy for optimization of solar photovoltaic array under non-uniform illumination conditions. 2011 Thirty-seventh IEEE photovoltaic specialists conference, 2011: p. 1859-64.

27. Vincenzo Li Vigni, Damiano La Manna, Eleonora Riva Sanseverino, Vincenzo di Dio, Pietro Romano, Pietro di Buono, Maurizio Pinto, Rosario Miceli and Costantino Giaconia, Proof of Concept of an Irradiance Estimation System for Reconfigurable Photovoltaic Arrays. Energies, 2015. 8: p. 6641-6657.

28. Eleonora Riva Sanseverino, Costantino Giuseppe Giaconia, Pietro Romano, Vincenzo Li Vigni, Marco Annello, Vincenzo Tirrasi, An optimization device for Series Parallel connected PV plants. International Conference on Applications in Electronics Pervading Industry, Environment and Society, 2016: p. 227-236.

29. Luis D. Murillo-Soto, Carlos Meza, Voltage measurement in a reconfigurable solar array with seriesparallel topology. 2017 IEEE 37th Central America and Panama Convention (CONCAPAN XXXVII), 15- 
17 Nov. 2017.

30. Badwaik, K.N., Reconfiguration Methods for Solar Photovoltaic array And Economic Evolution of Solar Cell. International Journal of Advance Engineering and Research Development, July -2017. 4(7).

31. Paula dos Santos Vicente, Tales Cleber Pimenta, Enio Roberto Ribeiro, Photovoltaic Array Reconfiguration Strategy for Maximization of Energy Production. International Journal of Photoenergy, 2015.

32. Hoare, C.A.R., Algorithm 64: Quicksort. Communications of the ACM, July 1961 4(7): p. 321.

33. Yousef Mahmoud, Ehab F. El-Saadany, Enhanced Reconfiguration Method for Reducing Mismatch Losses in PV Systems. IEEE JOURNAL OF PHOTOVOLTAICS, NOVEMBER 2017. 7.

34. Viola F., Romano P., Miceli R., Spataro C., Schettino G., Technical and economical evaluation on the use of reconfiguration systems in some EU countries for PV plants, (2017) IEEE Transactions on Industry Applications, 53 (2), art. no. 7736973, pp. 1308-1315.

35. Caruso, M., Di Noia, L.P., Romano, P., Schettino, G., Spataro, C., Viola, F., PV reconfiguration systems: A technical and economic study, (2017) Journal of Electrical Systems, 13 (1), pp. 55-73

36. Livreri, P., Caruso, M., Castiglia, V., Pellitteri, F., Schettino, G., Dynamic reconfiguration of electrical connections for partially shaded PV modules: Technical and economical performances of an Arduino-based prototype, (2018) International Journal of Renewable Energy Research, 8 (1), pp. 336-344. 